\title{
Review Article \\ Review of Recent Development on Preparation, Properties, and Applications of Cellulose-Based Functional Materials
}

\author{
Ya-Yu Li $\mathbb{D}^{1,2,3}$ Bin Wang, ${ }^{1}$ Ming-Guo Ma $\mathbb{D}^{1},{ }^{1}$ and Bo Wang ${ }^{1}$ \\ ${ }^{1}$ Engineering Research Center of Forestry Biomass Materials and Bioenergy, Beijing Key Laboratory of Lignocellulosic Chemistry, \\ College of Materials Science and Technology, Beijing Forestry University, Beijing 100083, China \\ ${ }^{2}$ College of Chemical Engineering, Xinjiang Agricultural University, Urumqi, Xinjiang 830052, China \\ ${ }^{3}$ Xinjiang Blue Ridge Tunhe Profiles Co., Ltd., Changji, Xinjiang 831100, China
}

Correspondence should be addressed to Ming-Guo Ma; mg_ma@bjfu.edu.cn

Received 30 January 2018; Accepted 7 March 2018; Published 10 May 2018

Academic Editor: Hossein Roghani-Mamaqani

Copyright (C) 2018 Ya-Yu Li et al. This is an open access article distributed under the Creative Commons Attribution License, which permits unrestricted use, distribution, and reproduction in any medium, provided the original work is properly cited.

Cellulose is the most abundant biomass resource in the world. It can be transferred to various water soluble derivatives, biochemicals, and materials. In the second half of the 20th century, nanocellulose was extracted with unique properties such as optical transparency, high strength, and high surface area. These new forms of cellulose can be combined with other materials, mainly biopolymers, to form multifarious composites, which are used in all applications of human life. For convenience, to introduce the recent development of these cellulose-based functional composites, we divided them to seven categories, including biological applications, water treatment, sensor, reinforcing agent, energy storage materials, Pickering emulsion stabilizer, and other versatile applications. The preparation, properties, and applications of these functional composites were depicted.

\section{Introduction}

The depletion of petroleum-based resources and the attendant environmental problems, such as global warming, have stimulated considerable interest in the development of environmentally sustainable biomasses, which are composed of cellulose, hemicelluloses, and lignin. From this point of view, cellulose has some advantages, such as renewability, biodegradability, and environmental friendliness. Cellulose, with an annual production estimated to be over $7.5 \times 10^{10}$ tons [1], is the most abundant biomass resource in the world. Cellulose is a fascinating and almost inexhaustible sustainable natural polymer that has been used in the form of fiber or its derivatives for thousands of years, for a wide range of materials and products applications. Cellulose was firstly introduced in 1838 and has gained immense importance, compared with other synthetic polymers. From then on, cellulose was transferred to various derivatives, most of which are water soluble. As a result, its applications were extended to every aspect of society. The typical derivatives are carboxymethyl cellulose (CMC), cellulose acetate (CA), methyl cellulose
(MC), hydroxyethyl cellulose (HEC), (hydroxypropyl)methyl cellulose (HPMC), and so on. Cellulose is a linear chain polysaccharide with $1,000-15,000 \beta$ glucose units. A lot of asexisted hydrogen bonds make cellulose a semirigid polymer. This supermacromolecular structure endows cellulose with the ultrahigh strength of $150 \mathrm{MPa}[2,3]$.

The unique hierarchical architecture of natural cellulose consisting of nanoscale fibrils and crystallites allows the extraction of the nanoconstituents via mechanical and chemical methods or through a combination of both of these techniques. Along with the development of nanoscience and technology, the new forms of nanocellulose are extracted, for example, nanofibrils cellulose (NFC) and cellulose nanocrystals (CNCs). Isolated NFC is long, thin, and flexible formation composed of alternating crystalline and amorphous domains, whereas the as-obtained CNCs are rod-shaped crystalline particles released after splitting of the amorphous domains. Nanocellulose has recently gained significant attention in the materials community $[1,4]$. It has been the subject of a wide array of research efforts aimed at different applications, because of its availability, renewability, lightweight, 
nanoscale dimensionality, unique morphology, and unsurpassed quintessential physical and chemical properties $[5,6]$.

Bacterial cellulose (BC) is an extracellular polymer produced by many microorganisms. It can be used in biomedicine and bioelectronics. Combining with other materials, such as alginate, chitosan, starch, silk fibroin, sericin, and xylans, to form biocomposites, the mechanical and biological properties of cellulose-based functional materials will be enhanced. The applications of cellulosic materials can be extended far beyond the traditional applications areas. Obviously, cellulose-based functional materials are exceptionally important for humankind.

In this paper, considering the extensive applications of cellulose-based functional materials, the recent developments and applications potential of cellulose-based functional materials in various fields were reviewed.

\section{Biological Applications}

Cellulose-based functional materials have wide applications potential in biomedical fields. For example, Chang et al. [18] prepared the BC/gelatin composites with enhanced mechanical strength for nanobiomaterials applications by immersing alkaline treated BC in fish gelatins. Increasing gelatin concentrations enhanced the formation of doublenetwork structures, improving the mechanical strength and hydrophilic property of composites. Chitosan (CS) is produced from partial deacetylation of chitin, which is the second most abundant biopolymer in nature. Akhlaghi et al. [19] developed a drug delivery system by modifying the surface of as-oxidized CNCs with CS oligosaccharide. CNCCS functional composites showed a binding efficiency of $21.5 \%$ and a drug loading of $14 \%(\mathrm{w} / \mathrm{w})$. The in vitro drug release indicated that the composites revealed a fast release of up to $1 \mathrm{~h}$ at $\mathrm{pH} 8$, which could be used as biocompatible and biodegradable drug carriers for transdermal delivery applications. CNCs-fibrin functional nanocomposites were synthesized, composed of homogeneously dispersed oxidized CNCs in a fibrin matrix, with fibrin providing elasticity and oxidized CNCs providing strength [20]. The manipulation of degree of oxidation of CNCs and the CNCs-to-fibrin ratio resulted in the variation of strength and elongation of the nanocomposites. The molecular interaction between asoxidized CNCs and fibrin induced by the carbonyl group is a key to effective reinforcement. Multilayered thin films of CNC were prepared in a cationic xylans matrix for the detection of xylanase activity by means of the "spin-assisted electrostatic layer-by-layer self-assembly" method, in which CNCs and cationic xylans are alternatively deposited up to 10 times on a rotating silicon wafer [21].

Cellulose-based functional materials can be used in cancer therapy due to their good biocompatibility. Comb copolymer ethyl cellulose-g-poly(e-caprolactone) (EC-g-PCL) was prepared by living ring opening polymerization of ecaprolactone with ethyl cellulose as the macroinitiator and stannous octoate as the catalyst [22]. Further modification of EC-g-PCL was carried out with rhodamine $\mathrm{B}(\mathrm{RhB})$ and folate acid (FA) to obtain fluorescent and targeting functional EC-g-PCL-RhB/FA for achieving simultaneous identification and tracing of cancer cells. Such multifunctional comb copolymer had potential applications in the field of targeted drug release. Multifunctional amine-terminated fluorescein isothiocyanate- (FI-) and FA-modified generation 5 poly(amidoamine) (PAMAM) dendrimers (G5. $\left.\mathrm{NH}_{2}-\mathrm{FI}-\mathrm{FA}\right)$ were modified on electrospun CA nanofibers [7]. The asremaining dendrimer terminal amines were then acetylated to avoid the nonspecific binding of the fibrous mat with negatively charged cell membranes (Figure 1). The modification of FA-targeted G5 dendrimers rendered the CA nanofibers with excellent specificity to capture FA receptorsoverexpressing cancer cells via ligand-receptor interactions. This modification approach favored capturing different types of cancer cells and detecting cancer cells in the lymphatic system or bloodstream. In addition to EC and CA, CNC was also used as a core material surrounded by polymers to assemble drug release system. More recently, Golshan et al. [23] grafted poly(propylene imine) onto CNC first and then conjugated it with FA outside the composite particle. They found that the FA-conjugated systems had higher drug load and more sustainable drug release functionality. This as-synthesized dendrimer-grafted CNC nanoparticles can be used in cancer cell specific targeting.

Wang et al. [24] constructed the cellulose/phosphor hybrid hydrogels using epichlorohydrin as cross-linker with the phosphor particles tightly embedded in the macroporous cellulose matrix, which led to the 3-fold compressive strength, compared with the cellulose hydrogel. The hydrogels emitted relatively strong green fluorescence under a UV lamp, as well as high brightness and long-lasting afterglow. Hybrid hydrogels with strong afterglow could be detected both under the skin and in the stomach with and without excitation light, showing promising prospects as a candidate for bioimaging.

Polyaniline (PANI), an excellent conductive polymer, can be incorporated with cellulose to form nanocomposites with high conductivity. $\mathrm{Fu}$ et al. [25] synthesized and immobilized PANI nanorods onto CMC-modified NFCs for biosensing applications. The as-prepared laccase (Lac)/PANI/CMC/cellulose/glassy carbon electrode showed the excellent response characteristics with the detection limit of $0.374 \mu \mathrm{M}$ and the linear response range from $0.497 \mu \mathrm{M}$ to $2.27 \mathrm{mM}$, being comparable and even superior to many laccase biosensors based on other matrices in the detection of catechol. The PANI/CMC/NFC would be a promising substrate material for the construction of enzyme biosensors. Cellulose hydrogel was used as template to in situ synthesize PANI via the limited interfacial polymerization method [26], leading to one conductive side in the polymer. The hydrophobic PANI nanoparticles were immobilized in the hydrophilic cellulose via the physic acid as "bridge" at presence of water through hydrogen bonding interaction. The PANI/cellulose composite hydrogels exhibited tensile strength of $2.71 \mathrm{MPa}$ and biocompatibility as well as excellent guiding capacity for the sciatic nerve regeneration of adult Sprague-Dawley rats without any extra treatment.

The biocompatible composites with high mechanical strength have the potential applications in bone regeneration. Amino-propyl-triethoxysilane was immobilized onto the surface of the CA membrane [27]. Then sericin was 

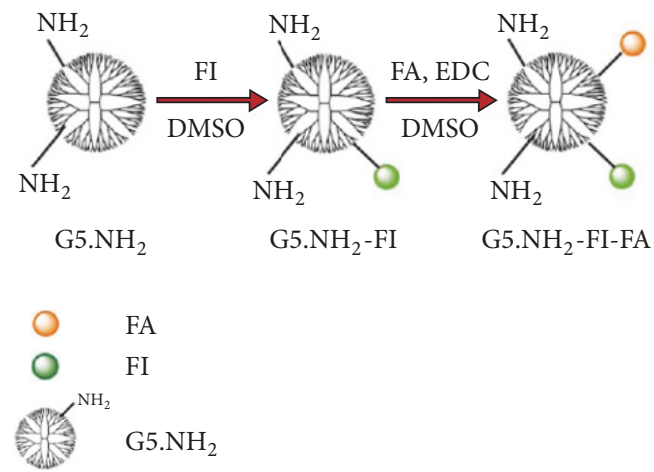

(a)

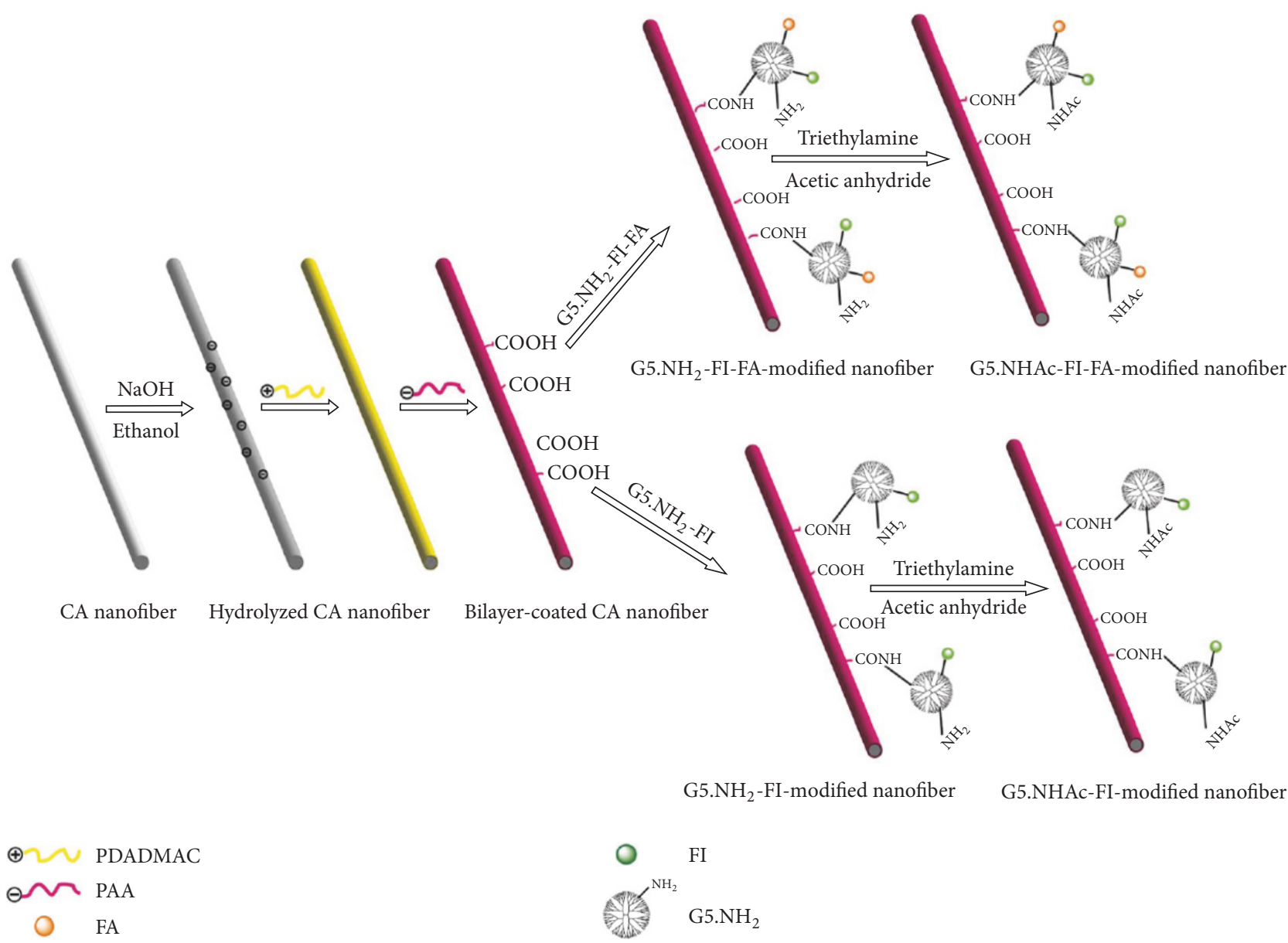

(b)

FIGURE 1: (a) Schematic representation of the synthesis of functionalized dendrimers and (b) the formation of dendrimer-functionalized CA nanofibers for cancer cell capture applications. Reprinted from [7].

immobilized through glutaraldehyde and amino-propyltriethoxysilane onto CA membrane. The as-attained CA membrane loading sericin was proved to hold great promise in bone regeneration. Porous silk fibroin/CNCs-CS composite scaffolds were prepared with excellent mechanical properties and biological compatibility by LbL assembly [28]. The hierarchical lamellar structure was formed by assembly of CNCs and CS onto the SF lamella. The porous silk
fibroin/CNCs-CS composites would be a promising tissue engineering scaffold for bone generation and implantation.

$\mathrm{CNCs}$ with much hydroxyl function on surface can be modified by grafting other compounds to extend their applications. Poly(vinyl acetate) (PVA) was grafted by CNCs (CNC-g-PVA) via surface initiated reversible additionfragmentation chain transfer and macromolecular design via the interchange of xanthates polymerization [29]. The 
CNC-g-PVA composites resulted in higher transparency and improved mechanical properties, compared with unmodified CNC nanocomposites. The addition of $5 \mathrm{wt} \% \mathrm{CNC}-\mathrm{g}-\mathrm{PVA}$ increased the modulus of neat PVA with as much as $154 \%$. Liu et al. [30] grafted quadruple hydrogen bonding moiety 2 -ureido- $4[1 \mathrm{H}]$-pyrimidone onto the surface of CNCs. The as-modified CNCs were demonstrated as excellent solid stabilizers to prepare high internal phase emulsions via onestep emulsification. Polymerizing the aqueous phase containing acrylamide and gelatin methacrylate resulted in elastic macroporous composite hydrogels. These macroporous composite hydrogels have good biocompatibility and promising cell adhesion and proliferation, employed as active biological scaffolds for tissue engineering.

Kresse et al. [8] introduced a paper-abetted lipid hydration in aqueous solutions method to produce giant liposomes (Figure 2). Microliters of lipids were deposited onto small pieces of dry chromatography paper and the volatile solvent evaporates rapidly, leaving behind a dried lipid film coating the cellulose fibers. The lipid-coated paper is placed into an aqueous "growth buffer" and numerous giant liposomes formed after an incubation. The giant liposomes were extracted from the paper and dispersed in a bulk solution. They expected the usefulness of paper as a platform for macromolecular self-assembly.

CMC film was modified by photo-cross-linking and chemical cross-linking methods, which can be utilized in the food packaging sector [31]. The results of surface hydrophobicity, water barrier, and mechanical properties were found to be a function of both treatments, among which photocross-linking treatment was more effective than the chemical cross-linking process. Cheng et al. [32] prepared 2,2,6,6tetramethylpiperidine-1-oxyl- (TEMPO-) mediated oxidized $\mathrm{CNC} /$ alginate composite films and sponges and simultaneously performed traditional $\mathrm{Ca}^{2+}$ cross-linking. In vivo degradation tests indicated that all materials could be biodegraded completely without inflammatory reaction after three weeks. The as-obtained composite sponges without cytotoxicity had higher porosity and tensile strength, which performed a large abundance of wound exudate and improved the adsorption ability for platelets and erythrocytes to achieve a rapid hemostatic effect. These composites had the potential application in the field of wound healing.

Microfibrillated cellulose (MFC) and NFC are the long fiber-like forms of cellulose in micro- and nanowidth, respectively, which are the effective reinforcing fillers. Ultralight NFC aerogel microspheres were prepared for cell culture scaffold applications by spray-freeze-drying method [33]. The as-obtained materials were highly lightweight $\left(0.0018 \mathrm{~g} \mathrm{~cm}^{-3}\right)$ with high porous and excellent water uptake capacity ( $\left.100 \mathrm{gg}^{-1}\right)$. Drug delivery systems were synthesized based on NFC-titania nanocomposites grafted with three different types of model drugs such as diclofenac sodium, penicillamine-D, and phosphomycin [34]. The as-obtained nanocomposites could potentially be applied in transdermal drug delivery for anesthetics, analgesics, and antibiotics. A suspension of MFC was prepared from carrot by mechanical defibrillation and MFC reinforced starch edible films [35].
The starch composite films had a lower water vapor permeability and higher tensile strength than pure starch films. The large number of passages through the mechanical defibrillator resulted in less aggregation of MFC, making it possible to obtain a good interaction between MFC and starch matrix.

Recently, Vecbiskena and Rozenberga [36] obtained NFC via ammonium persulfate oxidation of bleached birch $\mathrm{Kraft}$ pulp and unmodified BC pellicles and prepared chitosanmatrix films in packaging industry or biomedicine. Chitosan matrix tuned by $\mathrm{BC}$ nanofibers resulted in an increase of the mechanical and biological properties of the biocomposite films. MFC was mixed with calcium peroxide with or without catalase to form multilayered MFC nanocomposites that allow modulation of the releases of hydrogen peroxide $\left(\mathrm{H}_{2} \mathrm{O}_{2}\right)$ or oxygen $\left(\mathrm{O}_{2}\right)$, respectively [37]. The release profile of $\mathrm{H}_{2} \mathrm{O}_{2}$ from the $\mathrm{MFC} /$ calcium peroxide nanocomposites up to five days was obtained and the suppression of cell proliferation was observed. The generation of oxygen played an important role in supporting cell proliferation. The MFC/ calcium peroxide nanocomposites can be used in wound sterilization and to accelerate wound healing. Cellulose/SrF $\mathrm{S}_{2}$ nanocomposites were synthesized for potential applications in medical health care, water treatment, and food packaging industry by the microwave-assisted method at $100^{\circ} \mathrm{C}$ for $20 \mathrm{~min}$ [38]. The cellulose content was found to have a certain influence on the morphology, crystal lattice, crystallinity, and thermostability of alkaline earth metal fluorides. More recently, the hydrophobic functionalization of three water soluble cellulose types of methyl cellulose, HEC, and HPMC with the anticancer was also reported for agrochemical applications [39].

For clear and careful comparison of the major aspects of these mentioned products for biological applications, the cellulose form, other materials, preparation method, compound mechanism, and product advantage of the cellulosebased functional materials were summarized in Table 1.

\section{Water Treatment and Separation Applications}

Cellulose-based functional materials are usually applied in separation field, especially in water treatment. Biopolymers such as chitosan-based nanofibers, lignocellulose, chitosan, chitin, cellulose, and lignin are known to adsorb heavy metal ions from aqueous solutions [40-42]. Cellulose-based functional materials offer good adsorption capacity for the applications in water treatment fields.

Wastewater Treatment. Cellulose-methyltrioctylammonium chloride blend polymeric sorbent was prepared for the adsorption of carcinogenic chromium(VI) by ultrasonication method [40]. The adsorption capacity of chromium(VI) calculated from Langmuir isotherm model was found to be $38.94 \mathrm{mg} \mathrm{g}^{-1}$ with adherence to the second-order kinetics. The adsorbent was regenerated using ascorbic acid as the reducing agent, where the toxic chromium is converted to the less toxic Cr(III). Martins et al. [43] described the anaerobic degradation of the Remazol Golden Yellow RNL using cellulose-immobilized riboflavin as the redox mediator. 


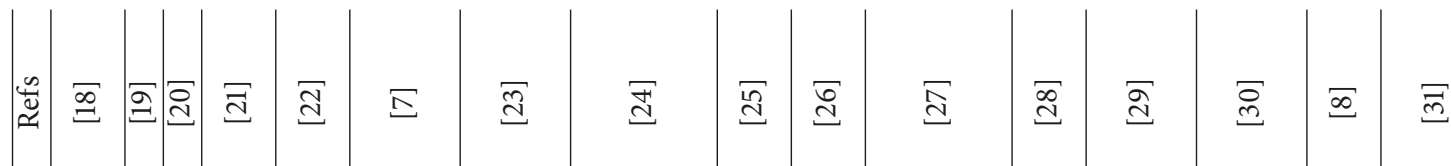

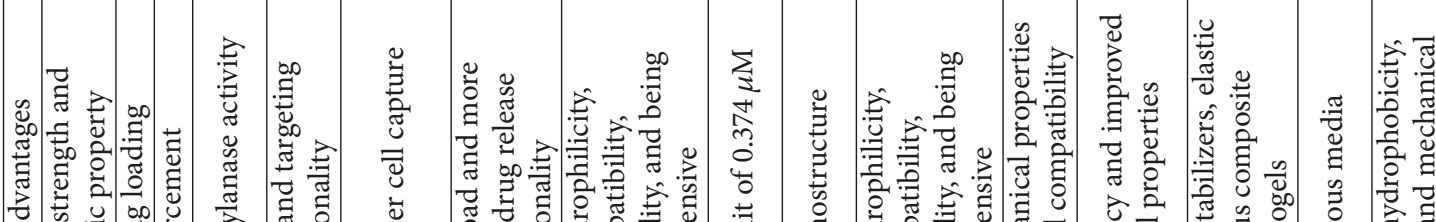

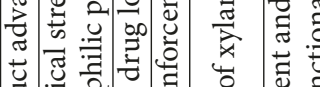

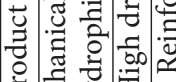

证

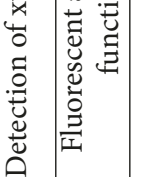

(2)

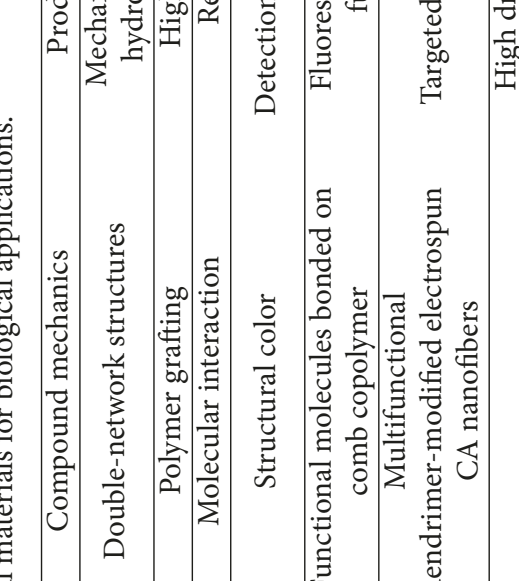

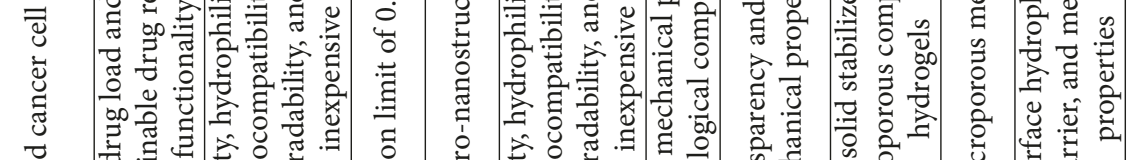

焉焉

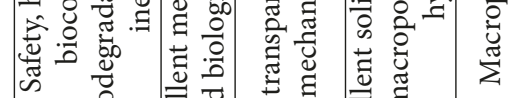

के

空密

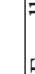




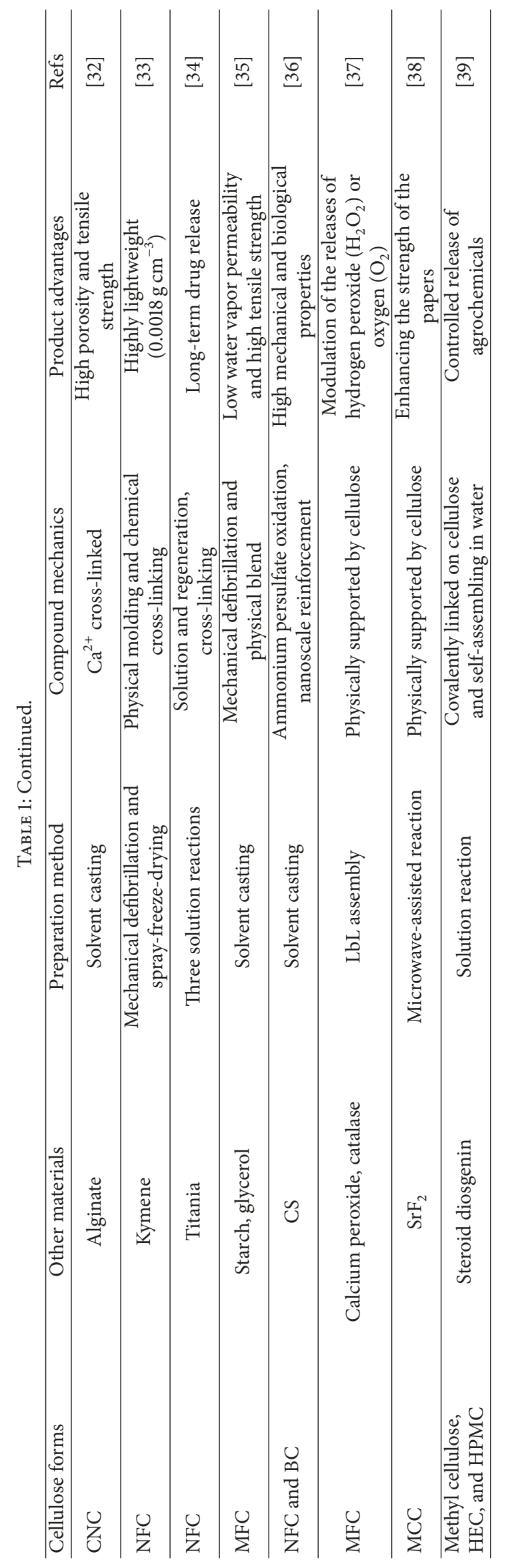


The riboflavin was covalently bound to cellulose and the asresulting material was chemically stable at $\mathrm{pH} 2$ to 9. The use of material increased the degradation rate constant of Remazol Golden Yellow RNL by $56 \%$ and allowed reduction of wastewater treatment costs.

Cellulose hydrogels were fabricated using the waste wheat straw as the source in $\mathrm{NaOH} / \mathrm{PEG}$ aqueous solution [41]. Then the well-dispersed superparamagnetic $\gamma-\mathrm{Fe}_{2} \mathrm{O}_{3}$ nanoparticles were encapsulated in the $3 \mathrm{D}$ architectures of cellulose aerogels. The as-prepared $\gamma-\mathrm{Fe}_{2} \mathrm{O}_{3} @ \mathrm{CA}$ composites exhibited superior magnetic responsiveness, which were easily actuated by an applied magnetic field. The hybrids also displayed rapid adsorption rate of $0.7364 \mathrm{~g} \cdot \mathrm{mg}^{-1} \cdot \mathrm{min}^{-1}$ and excellent adsorption ability of $10.2 \mathrm{mg} \mathrm{g}^{-1}$ to remove $\mathrm{Cr}(\mathrm{VI})$ heavy metal ions. Environmental friendly hydroxypropyl cellulose (HPC) hydrogels were fabricated with graphene oxide (GO) [44]. The as-obtained HPC-GO/HPC hydrogels exhibited excellent adsorption performance toward methylene blue. The cellulose/graphene composite was prepared by mixing dissolved cellulose with GO reducing by hydrazine hydrate [45]. The composites achieved higher adsorption levels than the other five sorbents such as graphite carbons, primary secondary amine, graphite carbon black, cellulose, and graphene for six triazine pesticides. The adsorption process fits the Langmuir model via the equilibrium adsorption isotherm. The adsorption efficiency of the cellulose/graphene composite was still over $85 \%$ after six times of recycling using a simple organic solvent.

Wang et al. [42] reported the amination of BC nanofiber membranes by a flush-coating and post-cross-linking method, which presented excellent adsorption performance for $\mathrm{Cu}^{2+}$ and $\mathrm{Pb}^{2+}$ ions from aqueous solutions. This cycle of adsorption and desorption was repeated for several times with good remaining adsorption performance (over $90 \%)$. The as-adsorbed $\mathrm{Cu}^{2+}$ ions can be reduced to copper nanoparticles and showed excellent catalytic performance for methylene blue reduction in aqueous solution. The catalytic performance can remain after several times of usage.

A carboxylated cellulose derivative (CTA) was prepared from the esterification of cellulose with 1,2,4-benzenetricarboxylic anhydride [46], as an adsorbent material to remove $\mathrm{Co}^{2+}, \mathrm{Cu}^{2+}$, and $\mathrm{Ni}^{2+}$ from monocomponent spiked aqueous solution. Langmuir model better fitted the experimental adsorption data and the maximum adsorption capacities estimated by this model were $0.749,1.487$, and $1.001 \mathrm{mmolg}^{-1}$ for $\mathrm{Co}^{2+}, \mathrm{Cu}^{2+}$, and $\mathrm{Ni}^{2+}$, respectively. Desorption and readsorption efficiencies were closer to $100 \%$, allowing the recovery of both metal ions and CTA adsorbent. The competitive adsorption of three binary systems $\mathrm{Cu}^{2+}$ $\mathrm{Co}^{2+}, \mathrm{Cu}^{2+}-\mathrm{Ni}^{2+}$, and $\mathrm{Co}^{2+}-\mathrm{Ni}^{2+}$ on CTA was evaluated in binary equimolar $(1: 1)$ metal ion aqueous solutions [47]. The CTA adsorbent displayed improved selectivity and good performance for the removal of $\mathrm{Co}^{2+}, \mathrm{Cu}^{2+}$, and $\mathrm{Ni}^{2+}$.

Cellulose and sugarcane bagasse were oxidized with an $\mathrm{H}_{3} \mathrm{PO}_{4}-\mathrm{NaNO}_{2}$ mixture to obtain adsorbent materials with high contents of carboxylic groups [48]. Adsorption isotherms were well fitted by the Langmuir and Konda models, with maximum adsorption capacities of $1117.8 \mathrm{mg} \mathrm{g}^{-1}$ and
$1223.3 \mathrm{mg} \mathrm{g}^{-1}$ on cellulose and $1018.2 \mathrm{mg} \mathrm{g}^{-1}$ and $682.8 \mathrm{mg} \mathrm{g}^{-1}$ on sugarcane bagasse. Desorption efficiencies were in the range of $50-52 \%$ and readsorption capacities varied from 65 to $81 \%$, showing the possibility of reuse of both adsorbent materials.

Štefelová et al. [9] explored the slow pyrolysis process of NFC from wood, Cladophora algae, and bacteria via various drying routes (Figure 3). Algae NFC with their large crystallites lead to surface area of $64 \mathrm{~m}^{2} \mathrm{~g}^{-1}$ substrates using conventional drying from aqueous suspension. NFC from wood resulted in chars with a good adsorption capacity for both anionic and cationic dyes. The porosity of the NFC substrate can be tuned via an ice-templating freeze-drying procedure reaching values as high as $99.7 \%$ and corresponding chars capable of absorbing $64-120 \mathrm{~g} \mathrm{~g}^{-1}$ of various oils and organic solvents.

$\mathrm{Ag} @ \mathrm{Fe}_{3} \mathrm{O}_{4} @ \mathrm{CNCs}$ nanocomposites were synthesized by a green microwave-assisted hydrothermal method [49]. CNCs showed a good reducing activity and played an important role in synthesizing of Ag particles. Longer reaction time was favored for the synthesis of more $\mathrm{Ag}$ and larger Ag@ $\mathrm{Fe}_{3} \mathrm{O}_{4}$ particles. Ag@ $\mathrm{Fe}_{3} \mathrm{O}_{4} @ \mathrm{CNC}$ nanocomposites exhibited good adsorption of dye solution, which showed potential applications in water treatment.

Separation Applications. Polyvinylidene fluoride-co-hexafluoropropylene membranes were fabricated containing different amounts of CNCs by electrospinning technique for application in membrane distillation [50]. Incorporation of CNCs in the matrix improved the tensile strength and Young's modulus and narrowed down the pore size distribution of the as-fabricated membranes. Liquid entry pressure was improved from $\sim 19$ psi to $\sim 27$ psi with the addition of $2 \mathrm{wt} . \%$ CNCs. It obtained the water flux of $10.2-11.5 \mathrm{~L} \mathrm{~h}^{-1} \mathrm{~m}^{-2}$ with salt rejection of $99 \%$ for these as-fabricated membranes CNCs-incorporated membranes. Multiwalled carbon nanotube (CNT)/CA nanocomposite membranes were prepared by phase inversion method using acetone as solvent and $20 \mathrm{wt}$ \% deionized water as nonsolvent [51]. Permeation rates were found to be improved by $54 \%$ with a minimal decrease in salt retention $(-6 \%)$ for the membranes with the lowest CNT content. Further addition of CNTs caused a reduction in permeation rates, attributed to the decreased porosity and surface area. The swelling behavior of poly(vinyl alcohol) (PVA) was controlled via aqueous blending of PVA with a modified form of cellulose as a reverse osmosis membrane [52]. The swelling capacity of PVA was reduced from $340 \%$ to $150 \%$. The tensile strength of wet PVA was improved by $1520 \%$ and the elastic modulus was improved by $1400 \%$. A $272 \mu \mathrm{m}$ thick membrane allowed a water flux value of $1.2 \mathrm{~L} \mathrm{~h}^{-1} \cdot \mathrm{m}^{-2}$ with a salt rejection of $98.8 \%$. Mesoporous organosilica spheres were prepared containing a cellulose tris(3,5-dimethylphenylcarbamate) based selector with porous structure, unique interfacial properties, and excellent mechanical strength [53]. This confirmed these spheres as chiral stationary phases with excellent chiral discrimination ability and solvent durability to chloroform. Iftekhar et al. [54] synthesized $\mathrm{Zn} / \mathrm{Al}$ layered double hydroxide intercalated 
(a) Deposit lipids in chloroform on paper

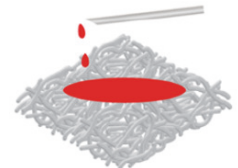

Film of dried lipids coats the fibers

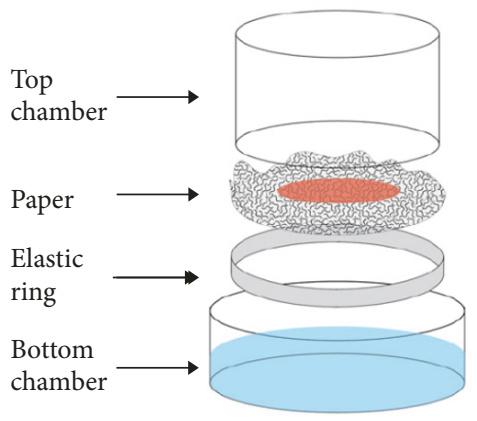

Assemble lipid-coated paper in cell culture insert

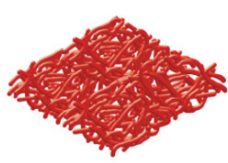

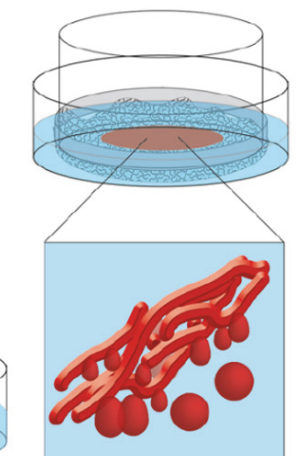

Giant liposomes form on cellulose fibers in the buffer (b) Incubating in "growth buffer"

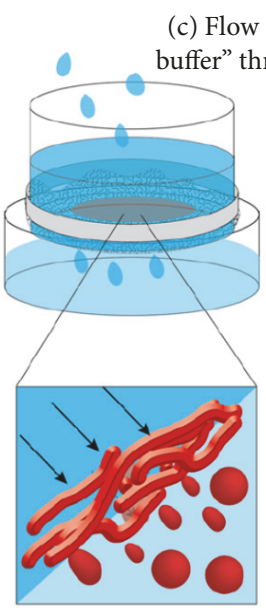

Flow of buffer extracts liposomes into bulk

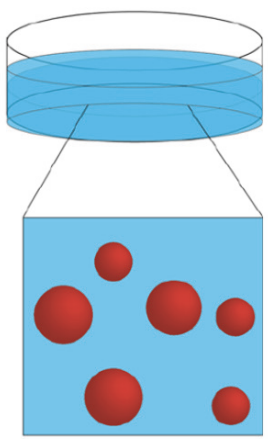

Liposomes free in bulk

Figure 2: Schematic of the paper-abetted lipid hydration in aqueous solutions method. The steps for the method are as follows: (a) Deposit a solution of lipids in chloroform onto the paper, allow the solvent to evaporate, and coat the cellulose fibers with a dry lipid film. (b) Place the dry lipid-coated paper into a desired aqueous solvent and incubate it for 30-120 min. Sandwiching the paper between polystyrene well inserts and elastic bands offers a convenient means of immobilizing the lipid-coated paper in a buffer-containing chamber. (c) Following a growth period, flow an extraction buffer through the paper to detach the liposomes into the bulk. Alternatively, use a cut pipet tip to aspirate the liposomes from the surface of the paper. Reprinted from [8].

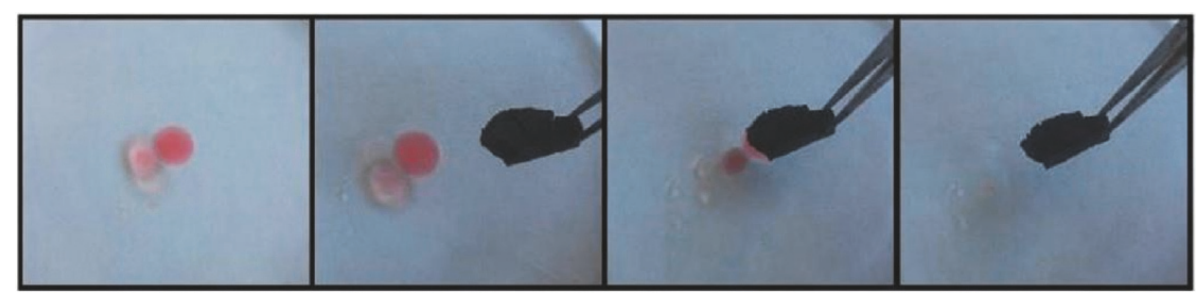

(a)

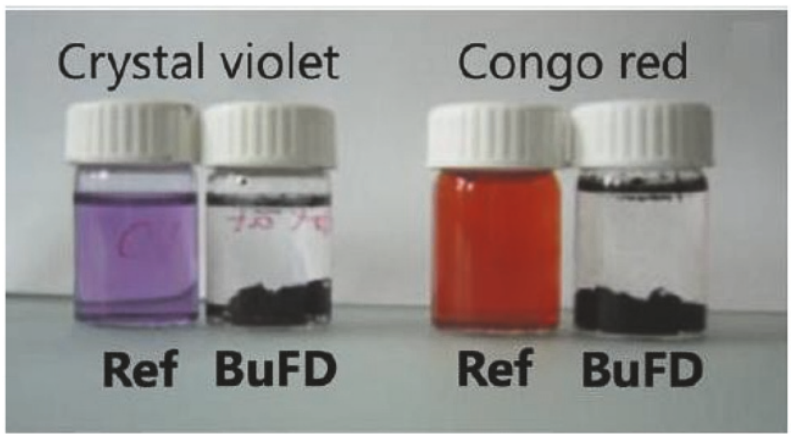

(b)

Figure 3: Photograph showing dodecane removal by freeze-dried NFC's char (a) and Crystal Violet and Congo Red solutions after dye adsorption by NFC char (b). Reprinted from [9]. 


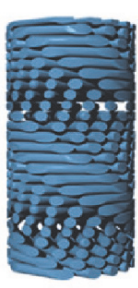

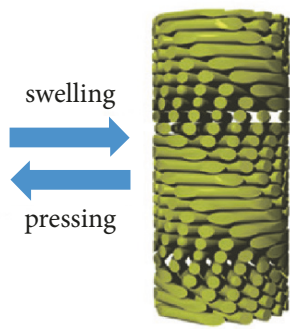

(a)
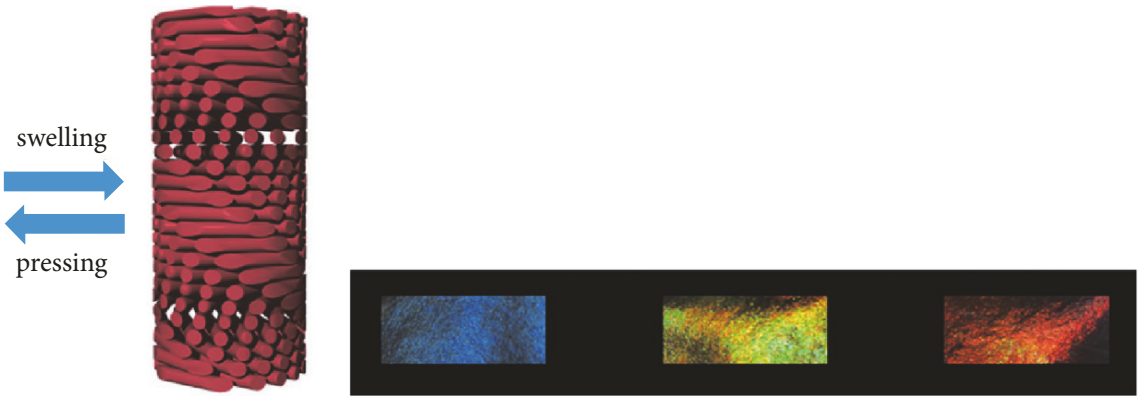

(b)

FIGURE 4: The schematic diagram of structure of photonic cellulose material with mesopores (a) and the procedure of color change by stimuli of swelling (b) and pressing (a). Reprinted from [10].

cellulose nanocomposite for the adsorption of $\mathrm{Y}^{3+}, \mathrm{La}^{3+}$, and $\mathrm{Ce}^{3+}$ by coprecipitation method. The nanocomposite revealed a good reusability up to five cycles and good adsorption and selectivity for $\mathrm{Y}^{3+}, \mathrm{La}^{3+}$, and $\mathrm{Ce}^{3+}$ in the presence of other ions.

\section{Sensor Applications}

Cellulose-based functional materials have the new coming applications as the sensing materials, which are in line with the science and technology development trend of artificial intelligence. Paper-based gold electrode arrays were assembled by hundreds of self-designed gold arrays on cellulose membranes using an inexpensive inkjet printer [55]. The as-resulting materials had several unique properties as thin-film sensor platforms, including good conductivity, excellent flexibility, high integration, and low cost. A paper-based solid-state electrochemical oxygen sensor was constructed using 1-butyl-3-methylimidazolium hexafluorophosphate electrolyte. The sensor liking a piece of paper possessed high sensitivity for $\mathrm{O}_{2}$ in a linear range from 0.054 to $0.177 \mathrm{v} / \mathrm{v} \%$, along with a low detection limit of $0.0075 \%$ and a short response time of less than $10 \mathrm{~s}$, foreseeing its promising applications in developing cost-effective and environmentfriendly paper-based electrochemical gas sensors.

Carbon nanotube- (CNT-) on-paper and CNT-cellulose composites were fabricated based on ammonia sensor [56]. The features of the present sensors included flexibility, low cost, and suitability for disposable applications. Compared to control sensors made on glass substrates, the paper-based sensor exhibited superior uniformity and repeatability.

Hybrid hydrogels were composed of BC nanofiber (nf$\mathrm{BC}$ ) and sodium alginate as a dual-stimuli responsive release system [57]. Compared with pure sodium alginate hydrogels, nf-BC/sodium alginate hybrid hydrogels presented a more stable and precise microstructure, $\mathrm{pH}$-responsive property, and effectively enhanced electroresponsive property.

The intriguing ability of CNCs to self-organize into a chiral nematic (cholesteric) liquid crystal phase with a helical arrangement had attracted significant interest, resulting in much research effort $[58,59]$. Giese et al. [10] reported a form of cellulose-derived material with tunable photonic properties and a unique mesoporous structure resulting from a supramolecular cotemplating method. Composites of CNCs and a urea-formaldehyde resin organized into a chiral nematic assembly, which yielded a chiral nematic mesoporous continuum of desulfated CNCs after alkaline treatment. The mesoporous photonic cellulose films undergo rapid and reversible changes in color upon swelling, which can be used for pressure sensing (Figure 4). These active mesoporous cellulosic materials had potential applications in biosensing, optics, functional membranes, chiral separation, and tissue engineering.

The sensitive balance was researched between glass formation and liquid crystal self-assembly that governed the formation of the desired helical structure [60]. In comparison with the corresponding self-assembly processes of other rodlike nanoparticles such as carbon nanotubes and $f d$ virus particles, CNCs displayed liquid crystal ordering phenomena. Water soluble carbon dots were synthesized by ionothermal treatment of cellulose with $\mathrm{SO}_{3} \mathrm{H}$-functionalized acidic ionic liquid as a catalyst in 1-butyl-3-methylimidazolium chloride $([\mathrm{Bmim}] \mathrm{Cl})[61]$. The as-synthesized carbon dots exhibited near-spherical morphology with an average diameter of $8.0 \mathrm{~nm}$ and a certain degree of sensitivity and selectivity for $\mathrm{Hg}^{2+}$, indicating that the carbon dots had potential applications as "turn-off" fluorescent sensors for the detection of $\mathrm{Hg}^{2+}$ in aqueous solution.

$\mathrm{BC}$ nanopaper was explored to fabricate disposable platforms for optical sensing [11]. Two types of plasmonic nanopaper, such as silver nanoparticles-BC (AgNPs-BC) and gold nanoparticles-BC (AuNPs-BC), and two types of photoluminescent nanopaper, such as upconversion nanoparticlesBC (UCNPs-BC) and quantum dots-BC (QD-BC), were obtained using different nanomaterials (Figure 5). BC nanopaper displayed the optical transparency, porosity, hydrophilicity, and amenability to chemical modification. BC was applied as an advantageous platform of small volumes of optically active nanomaterials.

Well suspended graphene@CNCs aqueous colloids were prepared in rubber composites for chemical sensing applications by the CNCs-mediated reduction of graphene oxide [62]. The graphene@CNCs nanohybrids constructed an ordered 3D conductive structure for the fabrication of liquid 


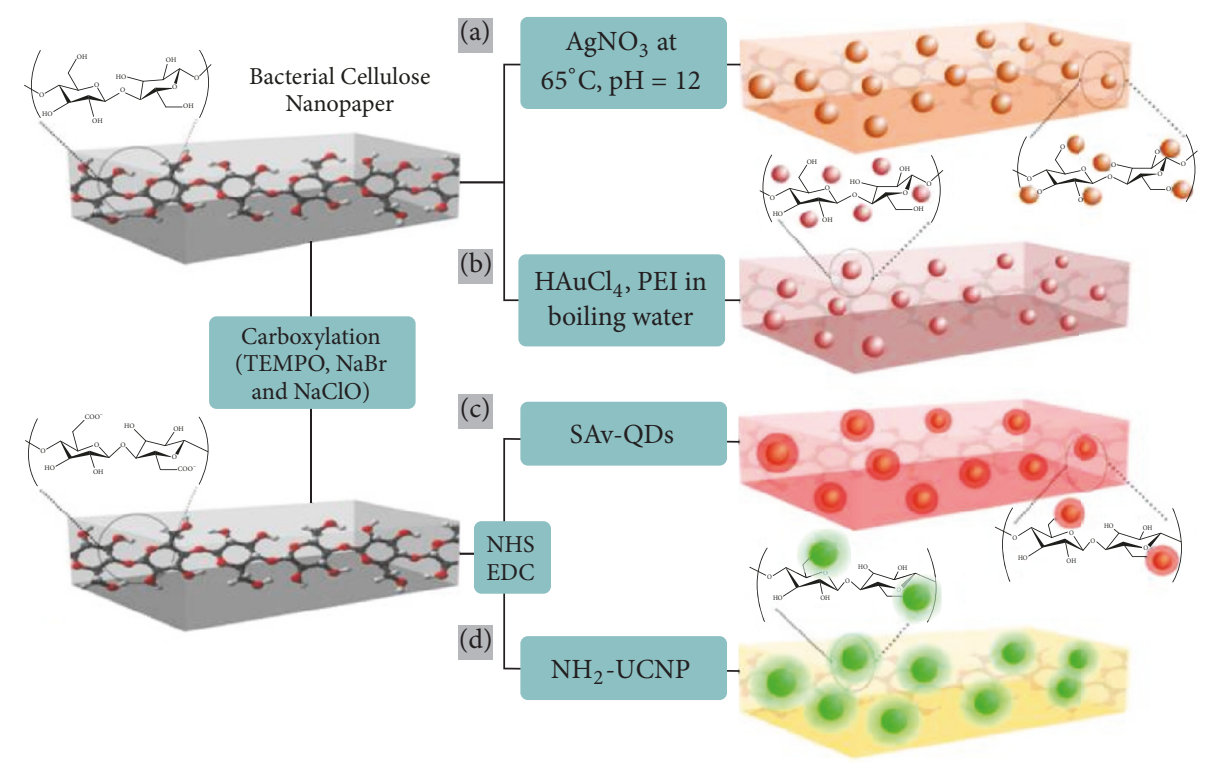

Silver Nanoparticles (AgNPs)

Gold Nanoparticles (AuNPs)

Streptavidin-CdSe@ZnS Quantum Dots (SAv-QDs)

$\mathrm{NaYF}_{4}: \mathrm{Yb}^{3+} @ \mathrm{Er}^{3+} \& \mathrm{SiO}_{2}-\mathrm{NH}_{2}$ Upconversion Nanoparticles $\left(\mathrm{NH}_{2}-\mathrm{UCNP}\right)$

FIGURE 5: Schematic of the proposed nanopaper-based composites. (A and B) Fabrication of plasmonic nanopaper: (A) silver nanoparticle/bacterial cellulose nanopaper conjugate (AgNP-BC); (B) gold nanoparticle/bacterial cellulose nanopaper conjugate (AuNP-BC). (C and D) Fabrication of photoluminescent nanopaper: (C) streptavidin-coated CdSe@ZnS quantum dot/bacterial cellulose nanopaper conjugate (QDBC); (D) aminosilica-coated NaYF4:Yb $\mathrm{Yb}^{3+} @ \mathrm{Er}^{3+}$ upconversion nanoparticle/bacterial cellulose nanopaper conjugate (UCNP-BC). Reprinted from [11].

sensors capable of sensing and discriminating various solvent leakage in chemical industry as well as environmental monitoring.

Cellulose-based smart materials with the grafted stimuli responsive side polymer chains have potential applications in various fields such as active packaging, biosensors, tissue engineering, antimicrobial surfaces, separation and detection, smart clothing, and drug release system. A proteinnanocellulose paper was developed for sensing copper ions at the nano- to micromolar level [12]. The cyanobacterial Cphycocyanin was loaded into a TEMPO-oxidized nanofibrillated cellulose (TONFC) matrix for copper ions (Figure 6). TONFC had a stabilizing effect on the sensing molecule without addition of any preservatives. The biosensor could reliably detect copper ion contents with a lower detection limit of $200 \times 10^{-9} \mathrm{M}$. The results showed that biosensor was suitable for the analysis of complex medical samples such as human serum filtrate. Haqani et al. grafted $N$-isopropylacrylamide-a thermoresponsive polymer and acrylic acida $\mathrm{pH}$-responsive polymer onto $\mathrm{CNC}$ and prepared two dual-sensitive drug release systems [63]. By the addition of poly( $N$-isopropylacrylamide) block to the poly(acrylic acid) grafted CNC, phase transition is observed at $32^{\circ} \mathrm{C}$. When the poly(acrylic acid) block is the outer layer, it observed phase transition at high temperatures and $\mathrm{pH}$-responsivity at $\mathrm{pH}$ 7.0-10.0. These products can be employed in drug delivery systems with controlled release of drugs by temperature and pH stimuli.

More recently, functional network hydrogels were fabricated as a high-performance, flexible, and wearable strain sensor by the interconnection between a "soft" homogeneous polymer network and a "hard" dynamic ferric $\left(\mathrm{Fe}^{3+}\right)$ crosslinked CNCs (CNCs-Fe ${ }^{3+}$ ) network [64]. The hydrogels demonstrated autonomously self-healing capability in only 5 min without the need of any stimuli or healing agents, ascribed to the reorganization of $\mathrm{CNCs}$ and $\mathrm{Fe}^{3+}$ via ionic coordination.

\section{Reinforcing Agent}

Cellulose-based functional materials can be used as reinforcement in structural materials. Cellulose is a natural hierarchical and porous structural material with high strength. CNCs have great potential as sustainable reinforcing materials for polymers, but there are a number of obstacles to commercialization that must first be overcome. High levels of water absorption, low thermal stabilities, poor miscibility with nonpolar polymers, and irreversible aggregation of the dried CNCs are among the greatest challenges to producing CNCs-polymer nanocomposites [65].

The CNCs from biomass had great potential as reinforcing agents for the manufacture of nanocomposites. Cellulose 


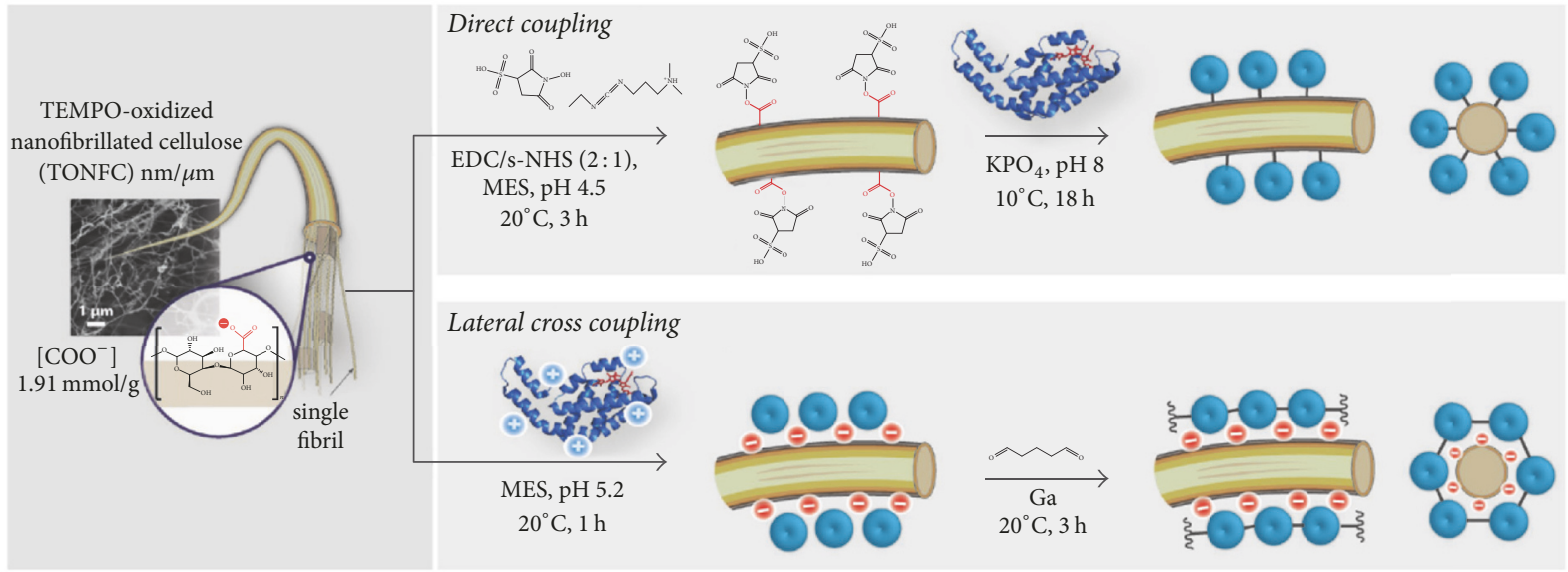

FIGURE 6: Functionalization strategies with expected high loading density used to immobilize the fluorescent sensing protein CPC to TEMPOoxidized nanofibrillated cellulose (TONFC). Direct coupling was achieved by incubating CPC with previously EDC/s-NHS-activated TONFC suspensions. Lateral cross coupling combined physical immobilization of CPC to TONFC with subsequent glutaraldehyde-mediated coupling of CPC molecules. Reprinted from [12].

fibers were isolated from Moroccan sugar cane bagasse by using three distinct stages for the applications as a reinforcing agent in low density polyethylene [66]. It found an enhancement on mechanical properties of composites including a gain of $72 \%$ in Young's modulus and a gain of $85 \%$ in flexural modulus at $25 \mathrm{wt}$.\% fiber loading, as a result of a good interface adhesion between cellulose fibers and matrix. CNCs were also extracted from corncob for application as reinforcing agent in nanocomposites [67]. The CNCs/PVA composites showed an improved tensile strength of $140.2 \%$ with only $9 \%$ (wt.\%) CNCs. The crystallinity index was found to have a greater influence on the tensile properties than the aspects ratio. After that, CNCs were extracted from plant cell wall by using efficient techniques for application as reinforcing agent in polymers [68].

$\mathrm{CNCs}$ were modified with silane coupling agent $\mathrm{KH}-550$ as a reinforcing agent and biopolyester poly(3-hydroxybutyrate-co-4-hydroxybutyrate) $(\mathrm{P}(3,4) \mathrm{HB}) / \mathrm{STCNW}$ nanocomposites were prepared by the solution casting method [3]. The STCNCs enhanced hydrophobicity and facilitated the crystallization of $\mathrm{P}(3,4) \mathrm{HB}$, which greatly improved the tensile strength and elastic modulus of $\mathrm{P}(3,4) \mathrm{HB}$ composites. The miscibility of dried CNCs was enhanced with a nonpolar polymer (epoxy and polystyrene) as lightweight composites in transportation, infrastructure, and renewable energy applications [65]. CNCs were modified with PMMA grafts in water using two different free-radical redox initiators including Fenton's Reagent $\left(\mathrm{Fe}^{2+}, \mathrm{H}_{2} \mathrm{O}_{2}\right)$ and ceric ammonium nitrate for engineering applications [69]. Nanocomposites with PMMA modified CNCs possessed high storage moduli in the glassy and rubbery state, in accordance with an enhanced dispersion of CNCs. More recently, CNCs were modified via surface grafting of (2-Dodecen-1-yl) succinic anhydride in dimethylformamide [70]. The as-resulting materials exhibited good dispersibility in organic solvents with a wide range of polarity, a significant increase in tensile strength, and modulus in the nanocomposite.
Various forms of cellulose could be applied in papermaking as reinforcing agent, such as MFC [71], NFC [72, 73], CNC [13], and BC $[74,75]$. MFC was prepared as reinforcement for paper-making with sodium hydroxide-sodium sulphite by the mechanical treatment from rice straw, bagasse, and cotton stalk, respectively [71]. Composite sheet papers were prepared from bleached rice straw and bagasse pulps by adding different percentages of MFC. The MFC enhanced the mechanical and optical properties with low percentage of $5 \mathrm{wt} \%$, compared with $20 \mathrm{wt} \%$ for soft wood pulp. Functionalized NFC was produced by the ball milling method to improve the interface between the NFC and hydrophobic matrix [72]. NFC modified by succinic anhydride showed the enhanced hydrophilicity and gave a zeta potential of $-38.7 \mathrm{mV}$ due to carboxyl groups on the surface. The NFC modified by dodecyl succinic anhydride had excellent dispersibility in o-xylene and good compatibility with polyethylene. The polyethylene-NFC composites presented overall enhancement of mechanical properties. NFC was produced from corn and rape stalk pulps by bleaching, refining, and TEMPO-mediated oxidation for the applications as paper additives [73]. The combination of NFC and chitosan in recycled paper achieved the high tensile index values. Sun et al. [13] applied sodium periodate oxidation of CNCs for the applications as paper wet strength additive and investigated the effects of reaction conditions on the content of aldehyde groups and yield loss of the as-oxidized CNCs. The asoxidized CNCs were functioned as a nanosized additive, improving the bonding degree between cellulosic fibers (Figure 7).

Santos et al. [74] focused on lining papers with BC sheets as reinforcing material on model papers from Gluconacetobacter sucrofermentans. BC improved the quality of deteriorated paper without altering the information [75], which is a promising alternative material for the restoration of paper. PLA/MFC multilayer biocomposites were fabricated for sustainable barrier applications [76], whose oxygen 


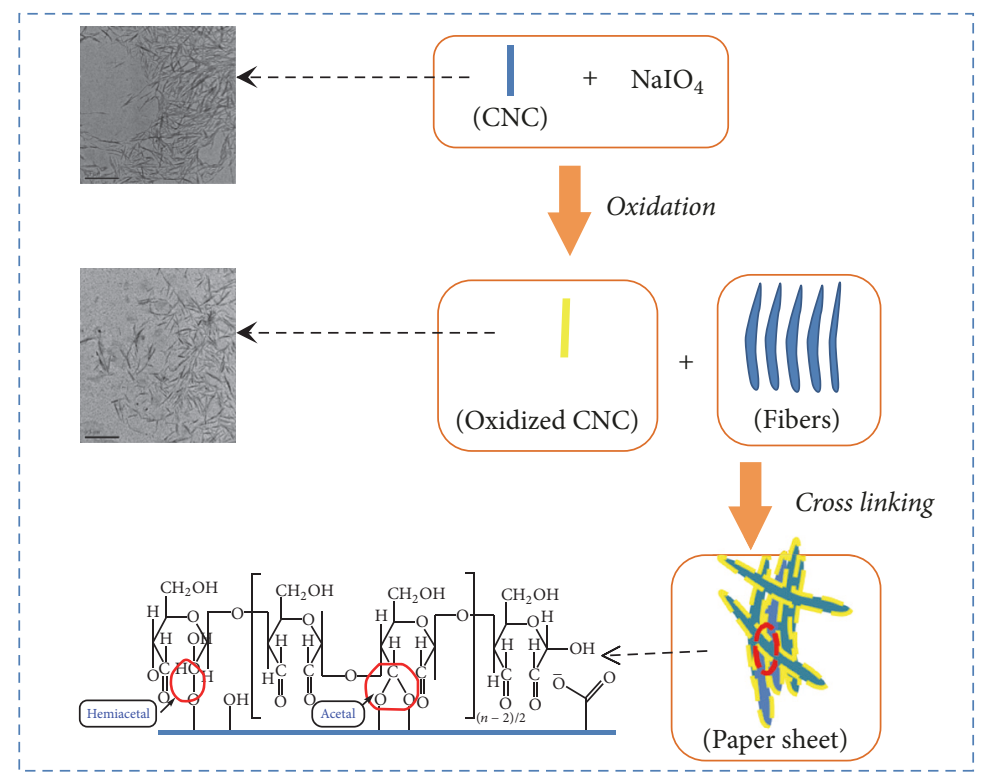

FIGURE 7: The proposed mechanism for the interaction between oxidized CNC and paper fibers. Reprinted from [13].

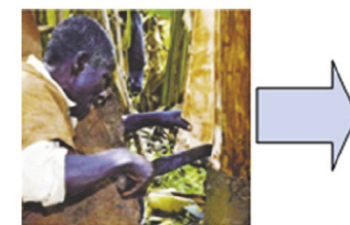

Ficus natalensis tree

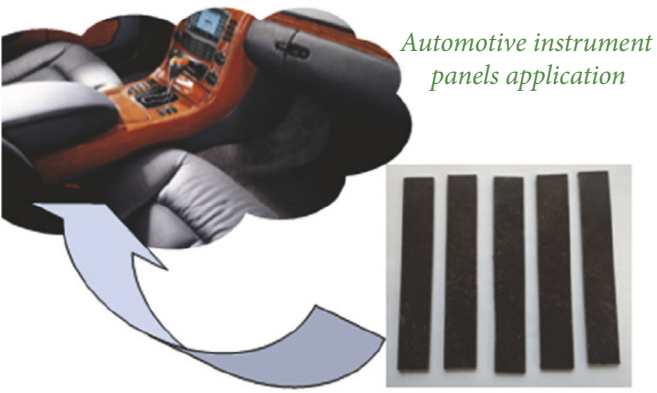

Bark cloth biocomposites

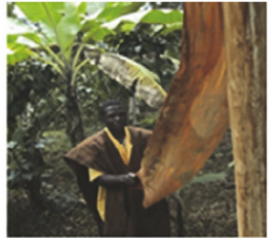

Raw fabric harvesting utomotive instrumen

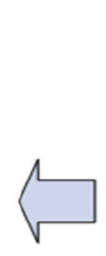

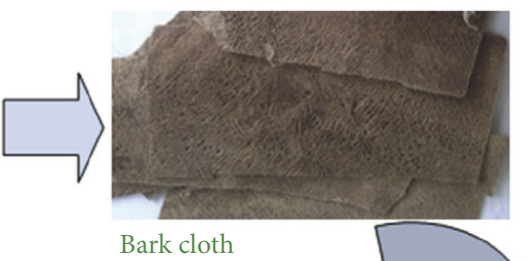

Bark cloth

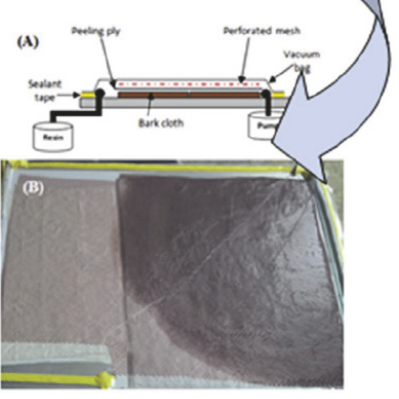

Bark cloth processing

FIGURE 8: Scheme of processing of bark cloth biocomposites for automotive applications. Reprinted from [14].

permeability in dry conditions showed a remarkable barrier effect, which was much lower than most of the conventional oil-based and novel biobased barrier solutions at $50 \%$ RH.

Biodegradable bark cloth reinforced green epoxy composites were developed for automotive instrument panel applications [14]. Figure 8 depicted the scheme of processing of bark cloth biocomposites for automotive applications. The static properties of epoxy composites showed a tensile strength of $33 \mathrm{MPa}$ and flexural strength of $207 \mathrm{MPa}$. Treatment of the fabric with alkali positively influenced the mechanical properties of the fabric reinforced biocomposites.

\section{Energy Storage Materials}

The as-fabricated energy storage materials include supercapacitors and lithium ion battery. Three-dimensional porous structures of reduced graphene oxide (RGO)/cellulose composites were fabricated for the potential applications in supercapacitors by a ball milling-assisted chemical reduction of GO [77]. The $3 \mathrm{D}$ porous structures of $\mathrm{RGO} /$ cellulose composites showed an electrical conductivity of $15.28 \mathrm{~S} \mathrm{~m}^{-1}$ due to the continuous RGO network with the high specific surface area and fast charge propagation in the composites. Conductive CNCs with high cycling stability were obtained for 


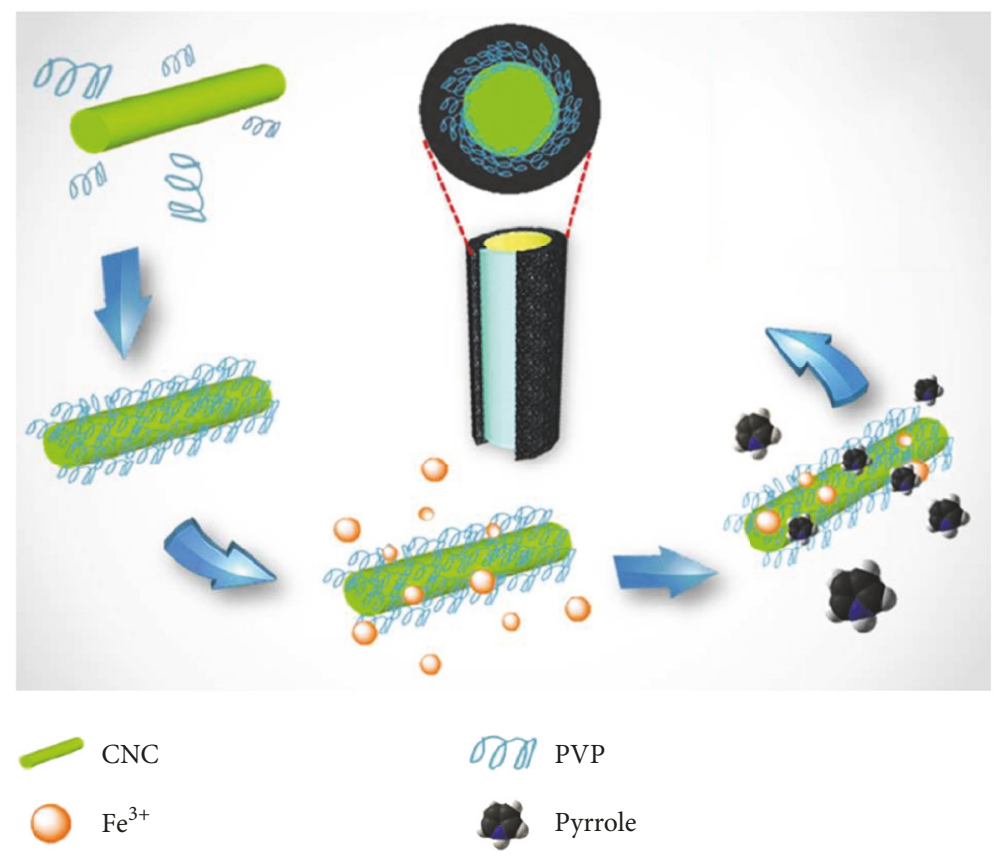

FIGURE 9: Schematic illustrating the formation of proposed core-shell polypyrrole coated CNC. poly( $N$-vinylpyrrolidone) was adsorbed onto the CNC surface prior to the polymerization to promote the homogeneous growth of polypyrrole shell. Reprinted from [15].

supercapacitor applications [15]. Core-shell polypyrrole on poly(N-vinylpyrrolidone) was coated with CNCs (Figure 9). The composites possessed a well-defined core-shell structure with well-preserved one-dimensional fibril geometry and significant improvement electrochemical performance.

Four cellulose nanofibril reinforced composite electrolytes were manufactured for lithium ion battery applications using NFC nanopaper as reinforcement in polymer matrix [78]. The composites, modified by an equimolar solution of propionyl chloride and acryloyl chloride, had an elastic modulus $>100 \mathrm{MPa}$ above $100^{\circ} \mathrm{C}$ and an ion conductivity of around $5 \times 10^{-5} \mathrm{~S} \mathrm{~cm}^{-1}$ at $25^{\circ} \mathrm{C}$. Snyder et al. [79] set up the criteria for structural batteries with $E^{\prime}>150 \mathrm{MPa}$ and $\sigma>1 \times$ $10^{-5} \mathrm{~S} \mathrm{~cm}^{-1}$.

Catalyst-free, flexible, mesoporous, and highly graphitized carbon aerogels with core-shell structure were synthesized based on BC/lignin composites [16]. These materials have potential applications of the carbon aerogels including oil/water separation, catalyst supports, sensors, and energy storage of supercapacitors and batteries (Figure 10). The large reversible deformations in carbon aerogels were attainable by utilizing the toughening effect of the $\mathrm{BC}$ nanofiber network. The blackberry-like structure and large mesopore concentration of these materials facilitated ion transportation and adsorption and led to their high areal capacitance.

Carboxymethyl cellulose and carboxymethyl kappacarrageenan were produced for green polymer electrolyte application [80]. The enhanced mechanical properties of CMKC with the addition of CMCE were obtained. The blend with wt $\%$ ratio of $60: 40$ yielded the most conductive film with conductivity of $3.25 \times 10^{-4} \mathrm{~S} \mathrm{~cm}^{-1}$.

\section{Pickering Emulsion Stabilizer}

Cellulose-based functional materials were developed as Pickering emulsion stabilizer due to their remarkable emulsifying performance. The palm olein-in-water Pickering emulsion was stabilized by $\mathrm{Fe}_{3} \mathrm{O}_{4}$-CNCs nanocomposites by the ultrasound-assisted in situ coprecipitation method [81]. The as-prepared $\mathrm{Fe}_{3} \mathrm{O}_{4}$-CNCs nanocomposites that stabilized Pickering emulsion were both $\mathrm{pH}$ and magnetic responsive, which may hold potential applications for biomedical and drug delivery as new generation of smart nanotherapeutic carrier. Yan et al. [82] also produced BC with ultrafine network architecture and $8-40 \mathrm{~nm}$ crystalline microfibrils in diameter by Acetobacter xylinum and bacterial CNCs by sulfuric acid hydrolysis followed by the oxidation of hydrogen peroxide for their applications in the stabilization of olive oil Pickering emulsion. Sulfuric acid hydrolysis of $\mathrm{BC}$ induced the removal of the amorphous components and the cleavage of the crystalline microfibrils, making bacterial CNCs possess the initiating decomposition temperature of $350^{\circ} \mathrm{C}$, which exhibited high thermal stability and good emulsifying performance in comparison with pure BC.

CNCs with high emulsifying performance were heterogeneously modified as emulsifiers for the formation of oil in water Pickering emulsions through a two-step chemical process including the hydrazone reaction and the amidation reaction [17]. Upon the replacement of $n$-hexane with a styrene/divinylbenzene mixed oil, cross-linked PS microspheres with amino-rich surfaces were created by the Pickering emulsion directed-radical copolymerization reaction, followed by acid treatment (Figure 11). 


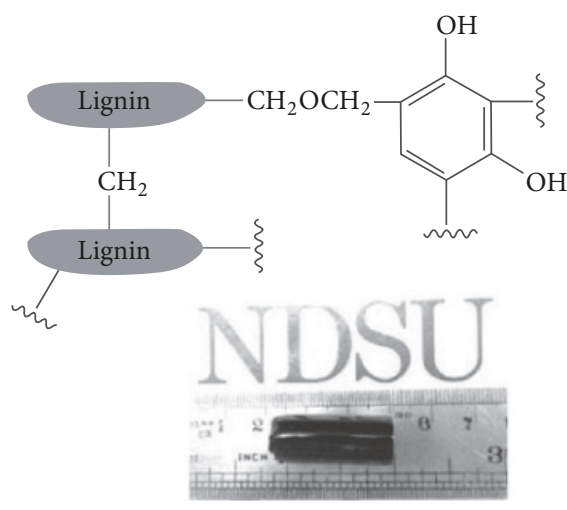

(a)

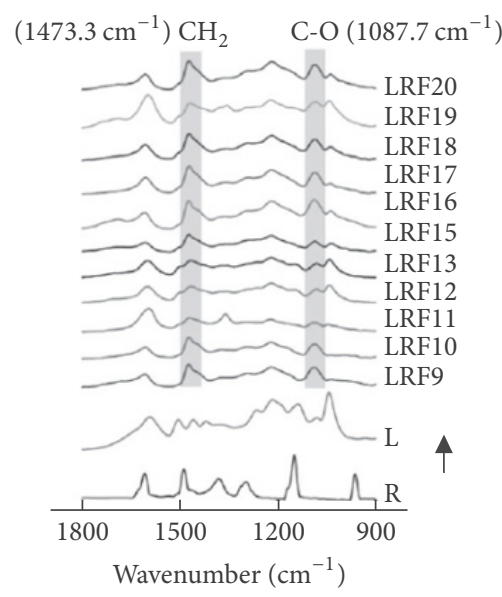

(b)

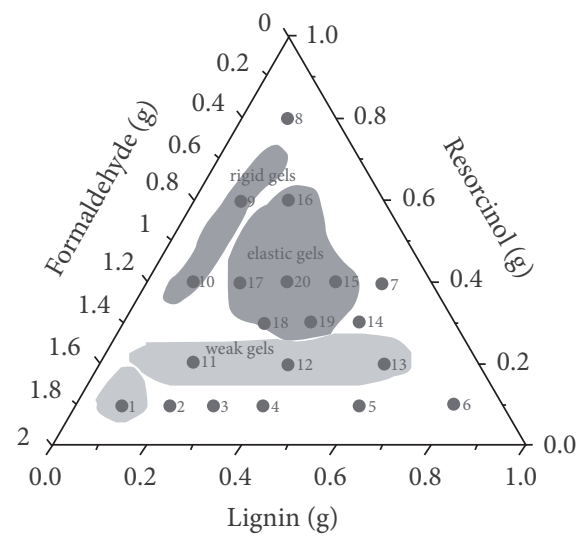

(c)

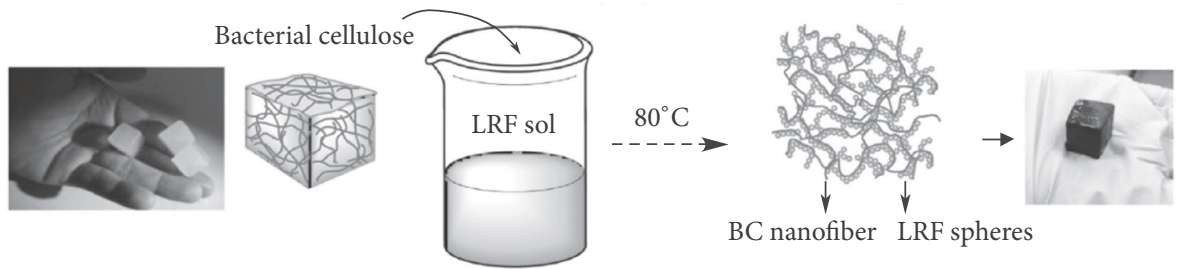

(d)

FIGURE 10: (a) Schematic macromolecular structure of an LRF hydrogel and LRF16 hydrogel sample. (b) FT-IR spectra of dried LRF gel powder. (c) Ternary plot of the gel property of various LRF hydrogels. (d) Process to produce BC-LRF hydrogel. Reprinted from [16].

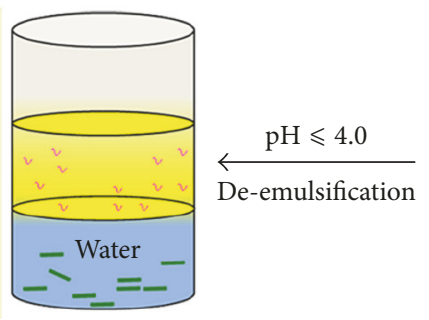

(a)

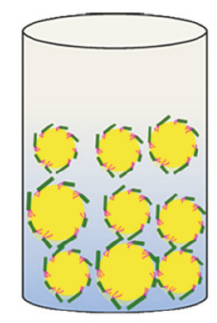

(b)

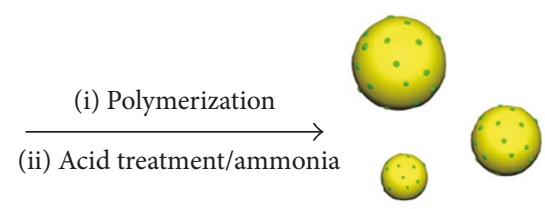

(c)

\footnotetext{
CNC-C 18

$n$-Hexane or St $+\mathrm{DVB}+\mathrm{AIBN}$

Amino group
}

Figure 11: Highly stable oil in water Pickering emulsions was formed at a low content of CNC-C18 (b). By tuning the pH of Pickering emulsions, 18-carbon alkyl chains were cleaved from CNCs and the emulsion was broken (a). Upon the replacement of n-hexane with a styrene/divinylbenzene mixed oil, cross-linked PS microspheres with amino-rich surfaces were created by the Pickering emulsion directedradical copolymerization reaction, followed by acid treatment (c). Reprinted from [17].

\section{Other Versatile Applications}

Besides the above-mentioned applications, cellulose-based functional materials still have other various versatile applications. Reza et al. [83] prepared magnetic hydrochar for biogas applications from the industrial MCC by adding ferrites during the hydrothermal carbonization. Recently, CdS quantum dot-functionalized CNCs were used as building blocks to fabricate thin films nanohybrids with high colloidal stability and narrow particle size distribution for anticounterfeiting applications via the LbL self-assembly method [84]. The as-modified poly(ethylene terephthalate) films with structural colors from thin-film interference and photoluminescence can be applied to anticounterfeiting applications. Porous cellulose beads were prepared as carrier for immobilization of $\mathrm{H}_{3} \mathrm{PW}_{12} \mathrm{O}_{40}$ with stronger catalytic activity for biodiesel production using ionic liquid as solvent and then further modified using four different reagents including 4-aminostyrene [85]. After using these materials for yellow horn oil esterification, it obtained the conversion yield of $96.22 \%$. Chen et al. [86] reported the CA-assisted graphene transfer method without introducing large cracks 
and residue contamination from polymers using CA as a holding layer to protect graphene during the transfer process. The CMC/AgNPs composites were designed for application as a benign corrosion inhibitor for $\mathrm{St} 37$ steel in $15 \% \mathrm{H}_{2} \mathrm{SO}_{4}$ medium by in situ reduction of $\mathrm{AgNO}_{3}$ using natural honey and incorporated into CMC matrix [87]. CMC/AgNPs composites were found to retard both the anodic and cathodic reactions.

\section{Conclusions}

Cellulose is the most abundant sustainable resource on the earth, which has been used for thousands of years by mankind. In 20th century, petrochemical resources occupied the primary status in industry, which was the main material source and elevated our life quality. Coming to 21st century, due to the increasing severe environmental problems, biomass materials received more attention, which substitute petrochemicals in all kinds of materials. Among these, cellulose-based functional materials are developed. As mentioned above, there are many reports on the applications of cellulose-based functional materials. Most progress was made on the fields of biological applications, water treatment, sensor, and reinforcing agent. Only a few reports were focused on energy storage materials and Pickering emulsion stabilizer. Considering the rapid development of energy storage materials, more efforts should be made on this field. Obviously, it is only the first step for us to obtain the cellulose-based functional materials. It is very important for the really applications by using these materials as resource to build functional devices. Moreover, there are many types of cellulose such as NFC, CNCs, BC, CMC, CA, MC, HEC, and HPMC. The types of cellulose also played an important role in the properties of cellulose-based functional materials. Furthermore, various materials such as organic and inorganic materials were applied to composite with cellulose to fabricate cellulose-based functional materials. In the next step, we should pay more attention to the interaction mechanism between cellulose and other materials. The cellulose-based functional materials will have a bright future with the progress of science and technology.

\section{Conflicts of Interest}

None of the authors have conflicts of interest.

\section{Acknowledgments}

Financial support from the Fundamental Research Funds for the Central Universities (no. 2017ZY49) and Young Teachers Cultivating Scientific Research Project (no. XJEDU2016S042) of University Scientific Research Plan of Xinjiang Uygur Autonomous Region is gratefully acknowledged.

\section{References}

[1] Y. Habibi, "Key advances in the chemical modification of nanocelluloses," Chemical Society Reviews, vol. 43, no. 5, pp. 1519$1542,2014$.
[2] Q. Q. Wang, J. Y. Zhu, R. S. Reiner, S. P. Verrill, U. Baxa, and S. E. McNeil, "Approaching zero cellulose loss in cellulose nanocrystal (CNC) production: Recovery and characterization of cellulosic solid residues (CSR) and CNC," Cellulose, vol. 19, no. 6, pp. 2033-2047, 2012.

[3] R. H. Zhang, W. Zhang, H. Li, M. Ling, and Z. P. Liu, "Biopolyester $\mathrm{P}(3,4) \mathrm{HB}$-based nanocomposites reinforced by cellulose nanowhisckers," Journal of Forestry Engineering, vol. 1, no. 03, pp. 85-90, 2016.

[4] B. Huang, Q. L. Lu, and L. R. Tang, "Research progress of nanocellulose manufacture and application," Journal of Forestry Engineering, vol. 1, no. 05, pp. 1-9, 2016.

[5] A. Brinkmann, M. Chen, M. Couillard, Z. J. Jakubek, T. Leng, and L. J. Johnston, "Correlating Cellulose Nanocrystal Particle Size and Surface Area," Langmuir, vol. 32, no. 24, pp. 6105-6114, 2016.

[6] W. P. Flauzino Neto, M. Mariano, I. S. V. da Silva et al., "Mechanical properties of natural rubber nanocomposites reinforced with high aspect ratio cellulose nanocrystals isolated from soy hulls," Carbohydrate Polymers, vol. 153, pp. 143-152, 2016.

[7] Y. Zhao, X. Zhu, H. Liu et al., "Dendrimer-functionalized electrospun cellulose acetate nanofibers for targeted cancer cell capture applications," Journal of Materials Chemistry B, vol. 2, no. 42, pp. 7384-7393, 2014.

[8] K. M. Kresse, M. Xu, J. Pazzi, M. García-Ojeda, and A. B. Subramaniam, "Novel Application of Cellulose Paper As a Platform for the Macromolecular Self-Assembly of Biomimetic Giant Liposomes," ACS Applied Materials \& Interfaces, vol. 8, no. 47, pp. 32102-32107, 2016.

[9] J. Štefelová, V. Slovák, G. Siqueira et al., "Drying and Pyrolysis of Cellulose Nanofibers from Wood, Bacteria, and Algae for Char Application in Oil Absorption and Dye Adsorption," ACS Sustainable Chemistry \& Engineering, vol. 5, no. 3, pp. 2679-2692, 2017.

[10] M. Giese, L. K. Blusch, M. K. Khan, W. Y. Hamad, and M. J. Maclachlan, "Responsive mesoporous photonic cellulose films by supramolecular cotemplating," Angewandte Chemie International Edition, vol. 53, no. 34, pp. 8880-8884, 2014.

[11] E. Morales-Narváez, H. Golmohammadi, T. Naghdi et al., "Nanopaper as an Optical Sensing Platform," ACS Nano, vol. 9, no. 7, pp. 7296-7305, 2015.

[12] R. Weishaupt, G. Siqueira, M. Schubert et al., "A Protein-Nanocellulose Paper for Sensing Copper Ions at the Nano- to Micromolar Level," Advanced Functional Materials, vol. 27, no. 4, Article ID 1604291, 2017.

[13] B. Sun, Q. Hou, Z. Liu, and Y. Ni, “Sodium periodate oxidation of cellulose nanocrystal and its application as a paper wet strength additive," Cellulose, vol. 22, no. 2, pp. 1135-1146, 2015.

[14] S. Rwawiire, B. Tomkova, J. Militky, A. Jabbar, and B. M. Kale, "Development of a biocomposite based on green epoxy polymer and natural cellulose fabric (bark cloth) for automotive instrument panel applications," Composites Part B: Engineering, vol. 81, pp. 149-157, 2015.

[15] X. Wu, J. Tang, Y. Duan, A. Yu, R. M. Berry, and K. C. Tam, "Conductive cellulose nanocrystals with high cycling stability for supercapacitor applications," Journal of Materials Chemistry A, vol. 2, no. 45, pp. 19268-19274, 2014.

[16] X. Xu, J. Zhou, D. H. Nagaraju et al., "Flexible, highly graphitized carbon aerogels based on bacterial cellulose/lignin: Catalyst-free synthesis and its application in energy storage devices," Advanced Functional Materials, vol. 25, no. 21, pp. 3193-3202, 2015. 
[17] W. Du, J. Guo, H. Li, and Y. Gao, "Heterogeneously Modified Cellulose Nanocrystals-Stabilized Pickering Emulsion: Preparation and Their Template Application for the Creation of PS Microspheres with Amino-Rich Surfaces," ACS Sustainable Chemistry \& Engineering, vol. 5, no. 9, pp. 7514-7523, 2017.

[18] S.-T. Chang, L.-C. Chen, S.-B. Lin, and H.-H. Chen, "Nanobiomaterials application: Morphology and physical properties of bacterial cellulose/gelatin composites via crosslinking," Food Hydrocolloids, vol. 27, no. 1, pp. 137-144, 2012.

[19] S. P. Akhlaghi, R. C. Berry, and K. C. Tam, "Surface modification of cellulose nanocrystal with chitosan oligosaccharide for drug delivery applications," Cellulose, vol. 20, no. 4, pp. 1747-1764, 2013.

[20] E. E. Brown, D. Hu, N. Abu Lail, and X. Zhang, "Potential of nanocrystalline cellulose-fibrin nanocomposites for artificial vascular graft applications," Biomacromolecules, vol. 14, no. 4, pp. 1063-1071, 2013.

[21] A. Dammak, C. Moreau, N. Beury et al., "Elaboration of multilayered thin films based on cellulose nanocrystals and cationic xylans: Application to xylanase activity detection," Holzforschung, vol. 67, no. 5, pp. 579-586, 2013.

[22] C. Jian, C. Gong, S. Wang et al., "Multifunctional comb copolymer ethyl cellulose-g-poly( $\varepsilon$-caprolactone)- rhodamine B/folate: Synthesis, characterization and targeted bonding application," European Polymer Journal, vol. 55, no. 1, pp. 235-244, 2014.

[23] M. Golshan, M. Salami-Kalajahi, H. Roghani-Mamaqani, and M. Mohammadi, "Poly(propylene imine) dendrimer-grafted nanocrystalline cellulose: Doxorubicin loading and release behavior," Polymer (United Kingdom), vol. 117, pp. 287-294, 2017.

[24] Z. Wang, X. Fan, M. He et al., "Construction of cellulose-phosphor hybrid hydrogels and their application for bioimaging," Journal of Materials Chemistry B, vol. 2, no. 43, pp. 7559-7566, 2014.

[25] J. Fu, Z. Pang, J. Yang, F. Huang, Y. Cai, and Q. Wei, "Fabrication of polyaniline/carboxymethyl cellulose/cellulose nanofibrous mats and their biosensing application," Applied Surface Science, vol. 349, pp. 35-42, 2015.

[26] D. Xu, L. Fan, L. Gao et al., "Micro-Nanostructured Polyaniline Assembled in Cellulose Matrix via Interfacial Polymerization for Applications in Nerve Regeneration," ACS Applied Materials \& Interfaces, vol. 8, no. 27, pp. 17090-17097, 2016.

[27] S. I. Voicu, R. M. Condruz, V. Mitran et al., "Sericin Covalent Immobilization onto Cellulose Acetate Membrane for Biomedical Applications," ACS Sustainable Chemistry \& Engineering, vol. 4, no. 3, pp. 1765-1774, 2016.

[28] J.-X. He, W.-L. Tan, Q.-M. Han, S.-Z. Cui, W. Shao, and F. Sang, "Fabrication of silk fibroin/cellulose whiskers-chitosan composite porous scaffolds by layer-by-layer assembly for application in bone tissue engineering," Journal of Materials Science, vol. 51, no. 9, pp. 4399-4410, 2016.

[29] A. Boujemaoui, S. Mazières, E. Malmström, M. Destarac, and A. Carlmark, "SI-RAFT/MADIX polymerization of vinyl acetate on cellulose nanocrystals for nanocomposite applications," Polymer (United Kingdom), vol. 99, pp. 240-249, 2016.

[30] S. Liu, M. Jin, Y. Chen et al., "High internal phase emulsions stabilised by supramolecular cellulose nanocrystals and their application as cell-adhesive macroporous hydrogel monoliths," Journal of Materials Chemistry B, vol. 5, no. 14, pp. 2671-2678, 2017.
[31] M. Shahbazi, S. J. Ahmadi, A. Seif, and G. Rajabzadeh, "Carboxymethyl cellulose film modification through surface photocrosslinking and chemical crosslinking for food packaging applications," Food Hydrocolloids, vol. 61, pp. 378-389, 2016.

[32] F. Cheng, C. Liu, X. Wei et al., "Preparation and Characterization of 2,2,6,6-Tetramethylpiperidine-1-oxyl (TEMPO)Oxidized Cellulose Nanocrystal/Alginate Biodegradable Composite Dressing for Hemostasis Applications," ACS Sustainable Chemistry \& Engineering, vol. 5, no. 5, pp. 3819-3828, 2017.

[33] H. Cai, S. Sharma, W. Liu et al., "Aerogel microspheres from natural cellulose nanofibrils and their application as cell culture scaffold," Biomacromolecules, vol. 15, no. 7, pp. 2540-2547, 2014.

[34] O. L. Galkina, V. K. Ivanov, A. V. Agafonov, G. A. Seisenbaeva, and V. G. Kessler, "Cellulose nanofiber-titania nanocomposites as potential drug delivery systems for dermal applications," Journal of Materials Chemistry B, vol. 3, no. 8, pp. 1688-1698, 2015.

[35] I. C. Guimarães, K. C. dos Reis, E. G. T. Menezes et al., "Cellulose microfibrillated suspension of carrots obtained by mechanical defibrillation and their application in edible starch films," Industrial Crops and Products, vol. 89, pp. 285-294, 2016.

[36] L. Vecbiskena and L. Rozenberga, "Nanocelluloses obtained by ammonium persulfate (APS) oxidation of bleached kraft pulp (BKP) and bacterial cellulose (BC) and their application in biocomposite films together with chitosan," Holzforschung, vol. 71, no. 7-8, pp. 659-666, 2017.

[37] C.-W. Chang and M.-J. Wang, "Preparation of microfibrillated cellulose composites for sustained release of $\mathrm{H} 2 \mathrm{O} 2$ or $\mathrm{O} 2$ for biomedical applications," ACS Sustainable Chemistry \& Engineering, vol. 1, no. 9, pp. 1129-1134, 2013.

[38] F. Deng, Y.-Y. Dong, S. Liu, B. Wang, M.-G. Ma, and X. Du, "Revealing the influences of cellulose on cellulose/SrF2 nanocomposites synthesized by microwave-assisted method," Industrial Crops and Products, vol. 85, pp. 258-265, 2016.

[39] J. Pérez Quiñones, C. Cela Mardare, A. Walter Hassel, and O. Brüggemann, "Self-assembled cellulose particles for agrochemical applications," European Polymer Journal, vol. 93, pp. 706716, 2017.

[40] S. Kalidhasan, A. Santhana KrishnaKumar, V. Rajesh, and N. Rajesh, "Ultrasound-assisted preparation and characterization of crystalline cellulose-ionic liquid blend polymeric material: A prelude to the study of its application toward the effective adsorption of chromium," Journal of Colloid and Interface Science, vol. 367, no. 1, pp. 398-408, 2012.

[41] C. C. Wan and J. Li, "Facile synthesis of well-dispersed superparamagnetic gamma-Fe2O3 nanoparticles encapsulated in three-dimensional architectures of cellulose aerogels and their applications for $\mathrm{Cr}(\mathrm{VI})$ removal from contaminated water," ACS Sustainable Chemistry \& Engineering, vol. 3, no. 9, pp. 2142-2152, 2015.

[42] J. Wang, X. Lu, P. F. Ng et al., "Polyethylenimine coated bacterial cellulose nanofiber membrane and application as adsorbent and catalyst," Journal of Colloid and Interface Science, vol. 440, pp. 32-38, 2015.

[43] L. R. Martins, B. E. L. Baêta, L. V. A. Gurgel, S. F. de Aquino, and L. F. Gil, "Application of cellulose-immobilized riboflavin as a redox mediator for anaerobic degradation of a model azo dye Remazol Golden Yellow RNL," Industrial Crops and Products, vol. 65, no. 1, pp. 454-462, 2015.

[44] X. Liu, Y. Zhou, W. Nie, L. Song, and P. Chen, "Fabrication of hydrogel of hydroxypropyl cellulose (HPC) composited with 
graphene oxide and its application for methylene blue removal," Journal of Materials Science, vol. 50, no. 18, pp. 6113-6123, 2015.

[45] C. Zhang, R. Z. Zhang, Y. Q. Ma et al., "Preparation of cellulose/graphene composite and its applications for triazine pesticides adsorption from water," ACS Sustainable Chemistry \& Engineering, vol. 3, no. 3, pp. 396-405, 2015.

[46] F. S. Teodoro, S. N. D. C. Ramos, M. M. C. Elias et al., "Synthesis and application of a new carboxylated cellulose derivative. Part I: Removal of $\mathrm{Co} 2+, \mathrm{Cu} 2+$ and $\mathrm{Ni} 2+$ from monocomponent spiked aqueous solution," Journal of Colloid and Interface Science, vol. 483, pp. 185-200, 2016.

[47] F. S. Teodoro, O. F. H. Adarme, L. F. Gil, and L. V. A. Gurgel, "Synthesis and application of a new carboxylated cellulose derivative. Part II: Removal of $\mathrm{Co} 2+, \mathrm{Cu} 2+$ and $\mathrm{Ni} 2+$ from bicomponent spiked aqueous solution," Journal of Colloid and Interface Science, vol. 487, pp. 266-280, 2017.

[48] L. R. Martins, J. A. V. Rodrigues, O. F. H. Adarme, T. M. S. Melo, L. V. A. Gurgel, and L. F. Gil, "Optimization of cellulose and sugarcane bagasse oxidation: Application for adsorptive removal of crystal violet and auramine-O from aqueous solution," Journal of Colloid and Interface Science, vol. 494, pp. 223-241, 2017.

[49] Y.-Y. Dong, S. Liu, Y.-J. Liu, L.-Y. Meng, and M.-G. Ma, "Ag@Fe3O4@cellulose nanocrystals nanocomposites: microwave-assisted hydrothermal synthesis, antimicrobial properties, and good adsorption of dye solution," Journal of Materials Science, vol. 52, no. 13, pp. 8219-8230, 2017.

[50] B. S. Lalia, E. Guillen, H. A. Arafat, and R. Hashaikeh, "Nanocrystalline cellulose reinforced PVDF-HFP membranes for membrane distillation application," Desalination, vol. 332, pp. 134-141, 2014.

[51] N. El Badawi, A. R. Ramadan, A. M. K. Esawi, and M. ElMorsi, "Novel carbon nanotube-cellulose acetate nanocomposite membranes for water filtration applications," Desalination, vol. 344, pp. 79-85, 2014.

[52] S. F. Anis, B. S. Lalia, and R. Hashaikeh, "Controlling swelling behavior of poly (vinyl) alcohol via networked cellulose and its application as a reverse osmosis membrane," Desalination, vol. 336, no. 1, pp. 138-145, 2014.

[53] X. Weng, Z. Bao, Z. Zhang et al., "Preparation of porous cellulose 3,5-dimethylphenylcarbamate hybrid organosilica particles for chromatographic applications," Journal of Materials Chemistry B, vol. 3, no. 4, pp. 620-628, 2015.

[54] S. Iftekhar, V. Srivastava, and M. Sillanpää, "Synthesis and application of $\mathrm{LDH}$ intercalated cellulose nanocomposite for separation of rare earth elements (REEs)," Chemical Engineering Journal, vol. 309, pp. 130-139, 2017.

[55] C. Hu, X. Bai, Y. Wang, W. Jin, X. Zhang, and S. Hu, "Inkjet printing of nanoporous gold electrode arrays on cellulose membranes for high-sensitive paper-like electrochemical oxygen sensors using ionic liquid electrolytes," Analytical Chemistry, vol. 84, no. 8, pp. 3745-3750, 2012.

[56] J. W. Han, B. Kim, J. Li, and M. Meyyappan, "A carbon nanotube based ammonia sensor on cellulose paper," Rsc Advances, vol. 4, no. 2, pp. 549-553, 2014.

[57] X. Shi, Y. Zheng, G. Wang, Q. Lin, and J. Fan, "PH- and electroresponse characteristics of bacterial cellulose nanofiber/sodium alginate hybrid hydrogels for dual controlled drug delivery," RSC Advances, vol. 4, no. 87, pp. 47056-47065, 2014.

[58] D. G. Gray, "Recent advances in chiral nematic structure and iridescent color of cellulose nanocrystal films," Nanomaterials, vol. 6, no. 11, pp. 213-221, 2016.
[59] Y. Y. Zhang, X. Wan, M. M. Mo, and D. G. Li, "Preparation of cellulose nanocrystal film and cholesteric liquid crystal pattern," Journal of Forestry Engineering, vol. 2, no. 04, pp. 103-108, 2017.

[60] J. P. F. Lagerwall, C. Schütz, M. Salajkova et al., "Cellulose nanocrystal-based materials: from liquid crystal self-assembly and glass formation to multifunctional thin films," NPG Asia Materials, vol. 6, article e80, 2014.

[61] C. Wang, C. Wang, P. Xu, A. Li, Y. Chen, and K. Zhuo, "Synthesis of cellulose-derived carbon dots using acidic ionic liquid as a catalyst and its application for detection of $\mathrm{Hg} 2+$," Journal of Materials Science, vol. 51, no. 2, pp. 861-867, 2016.

[62] J. Cao, X. Zhang, X. Wu, S. Wang, and C. Lu, "Cellulose nanocrystals mediated assembly of graphene in rubber composites for chemical sensing applications," Carbohydrate Polymers, vol. 140, pp. 88-95, 2016.

[63] M. Haqani, H. Roghani-Mamaqani, and M. Salami-Kalajahi, "Synthesis of dual-sensitive nanocrystalline cellulose-grafted block copolymers of $\mathrm{N}$-isopropylacrylamide and acrylic acid by reversible addition-fragmentation chain transfer polymerization," Cellulose, vol. 24, no. 5, pp. 2241-2254, 2017.

[64] Y.-J. Liu, W.-T. Cao, M.-G. Ma, and P. Wan, "Ultrasensitive Wearable Soft Strain Sensors of Conductive, Self-healing, and Elastic Hydrogels with Synergistic "soft and Hard" Hybrid Networks," ACS Applied Materials \& Interfaces, vol. 9, no. 30, pp. 25559-25570, 2017.

[65] D. M. Fox, R. S. Rodriguez, M. N. Devilbiss et al., "Simultaneously Tailoring Surface Energies and Thermal Stabilities of Cellulose Nanocrystals Using Ion Exchange: Effects on Polymer Composite Properties for Transportation, Infrastructure, and Renewable Energy Applications," ACS Applied Materials \& Interfaces, vol. 8, no. 40, pp. 27270-27281, 2016.

[66] A. Moubarik, N. Grimi, and N. Boussetta, "Structural and thermal characterization of Moroccan sugar cane bagasse cellulose fibers and their applications as a reinforcing agent in low density polyethylene," Composites Part B: Engineering, vol. 52, pp. 233238, 2013.

[67] H. A. Silvério, W. P. Flauzino Neto, N. O. Dantas, and D. Pasquini, "Extraction and characterization of cellulose nanocrystals from corncob for application as reinforcing agent in nanocomposites," Industrial Crops and Products, vol. 44, pp. 427-436, 2013.

[68] H.-M. Ng, L. T. Sin, T.-T. Tee et al., "Extraction of cellulose nanocrystals from plant sources for application as reinforcing agent in polymers," Composites Part B: Engineering, vol. 75, pp. 176-200, 2015.

[69] S. Spinella, C. Samuel, J.-M. Raquez, S. A. McCallum, R. Gross, and P. Dubois, "Green and Efficient Synthesis of Dispersible Cellulose Nanocrystals in Biobased Polyesters for Engineering Applications," ACS Sustainable Chemistry \& Engineering, vol. 4, no. 5, pp. 2517-2527, 2016.

[70] C. Miao and W. Y. Hamad, "Alkenylation of cellulose nanocrystals (CNC) and their applications," Polymer (United Kingdom), vol. 101, pp. 338-346, 2016.

[71] A. M. Adel, A. A. El-Gendy, M. A. Diab, R. E. Abou-Zeid, W. K. El-Zawawy, and A. Dufresne, "Microfibrillated cellulose from agricultural residues. Part I: Papermaking application,” Industrial Crops and Products, vol. 93, pp. 161-174, 2016.

[72] P. Huang, Y. Zhao, S. Kuga, M. Wu, and Y. Huang, "A versatile method for producing functionalized cellulose nanofibers and their application," Nanoscale, vol. 8, no. 6, pp. 3753-3759, 2016. 
[73] A. Balea, N. Merayo, E. De La Fuente, C. Negro, and Á. Blanco, "Assessing the influence of refining, bleaching and TEMPOmediated oxidation on the production of more sustainable cellulose nanofibers and their application as paper additives," Industrial Crops and Products, vol. 97, pp. 374-387, 2017.

[74] S. M. Santos, J. M. Carbajo, N. Gómez et al., "Use of bacterial cellulose in degraded paper restoration. Part I: application on model papers," Journal of Materials Science, vol. 51, no. 3, pp. 1541-1552, 2016.

[75] S. M. Santos, J. M. Carbajo, N. Gómez et al., "Use of bacterial cellulose in degraded paper restoration. Part II: application on real samples," Journal of Materials Science, vol. 51, no. 3, pp. 1553-1561, 2016.

[76] Ç. Meriçer, M. Minelli, M. G. D. Angelis et al., "Atmospheric plasma assisted PLA/microfibrillated cellulose (MFC) multilayer biocomposite for sustainable barrier application," Industrial Crops and Products, vol. 93, pp. 235-243, 2016.

[77] W. Ouyang, J. Sun, J. Memon, C. Wang, J. Geng, and Y. Huang, "Scalable preparation of three-dimensional porous structures of reduced graphene oxide/cellulose composites and their application in supercapacitors," Carbon, vol. 62, pp. 501-509, 2013.

[78] M. Willgert, S. Leijonmarck, G. Lindbergh, E. Malmström, and M. Johansson, "Cellulose nanofibril reinforced composite electrolytes for lithium ion battery applications," Journal of Materials Chemistry A, vol. 2, no. 33, pp. 13556-13564, 2014.

[79] J. F. Snyder, R. H. Carter, and E. D. Wetzel, "Electrochemical and mechanical behavior in mechanically robust solid polymer electrolytes for use in multifunctional structural batteries," Chemistry of Materials, vol. 19, no. 15, pp. 3793-3801, 2007.

[80] S. Rudhziah, M. S. A. Rani, A. Ahmad, N. S. Mohamed, and H. Kaddami, "Potential of blend of kappa-carrageenan and cellulose derivatives for green polymer electrolyte application," Industrial Crops and Products, vol. 72, pp. 133-141, 2015.

[81] L. E. Low, B. T. Tey, B. H. Ong, E. S. Chan, and S. Y. Tang, "Palm olein-in-water Pickering emulsion stabilized by Fe3O4cellulose nanocrystal nanocomposites and their responses to pH," Carbohydrate Polymers, vol. 155, pp. 391-399, 2017.

[82] H. Yan, X. Chen, H. Song et al., "Synthesis of bacterial cellulose and bacterial cellulose nanocrystals for their applications in the stabilization of olive oil pickering emulsion," Food Hydrocolloids, vol. 72, pp. 127-135, 2017.

[83] M. T. Reza, E. Rottler, R. Tölle, M. Werner, P. Ramm, and J. Mumme, "Production, characterization, and biogas application of magnetic hydrochar from cellulose," Bioresource Technology, vol. 186, pp. 34-43, 2015.

[84] L. Chen, C. Lai, R. Marchewka, R. M. Berry, and K. C. Tam, "Use of CdS quantum dot-functionalized cellulose nanocrystal films for anti-counterfeiting applications," Nanoscale, vol. 8, no. 27, pp. 13288-13296, 2016.

[85] D.-Y. Zhang, M.-H. Duan, X.-H. Yao, Y.-J. Fu, and Y.-G. Zu, "Preparation of a novel cellulose-based immobilized heteropoly acid system and its application on the biodiesel production," Fuel, vol. 172, pp. 293-300, 2016.

[86] M. Chen, G. Li, W. Li et al., "Large-scale cellulose-assisted transfer of graphene toward industrial applications," Carbon, vol. 110, pp. 286-291, 2016.

[87] M. M. Solomon, H. Gerengi, and S. A. Umoren, "Carboxymethyl Cellulose/Silver Nanoparticles Composite: Synthesis, Characterization and Application as a Benign Corrosion Inhibitor for St37 Steel in 15\% H2SO4 Medium," ACS Applied Materials \& Interfaces, vol. 9, no. 7, pp. 6376-6389, 2017. 


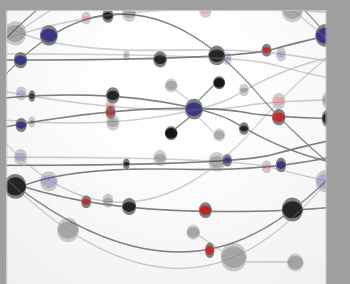

The Scientific World Journal
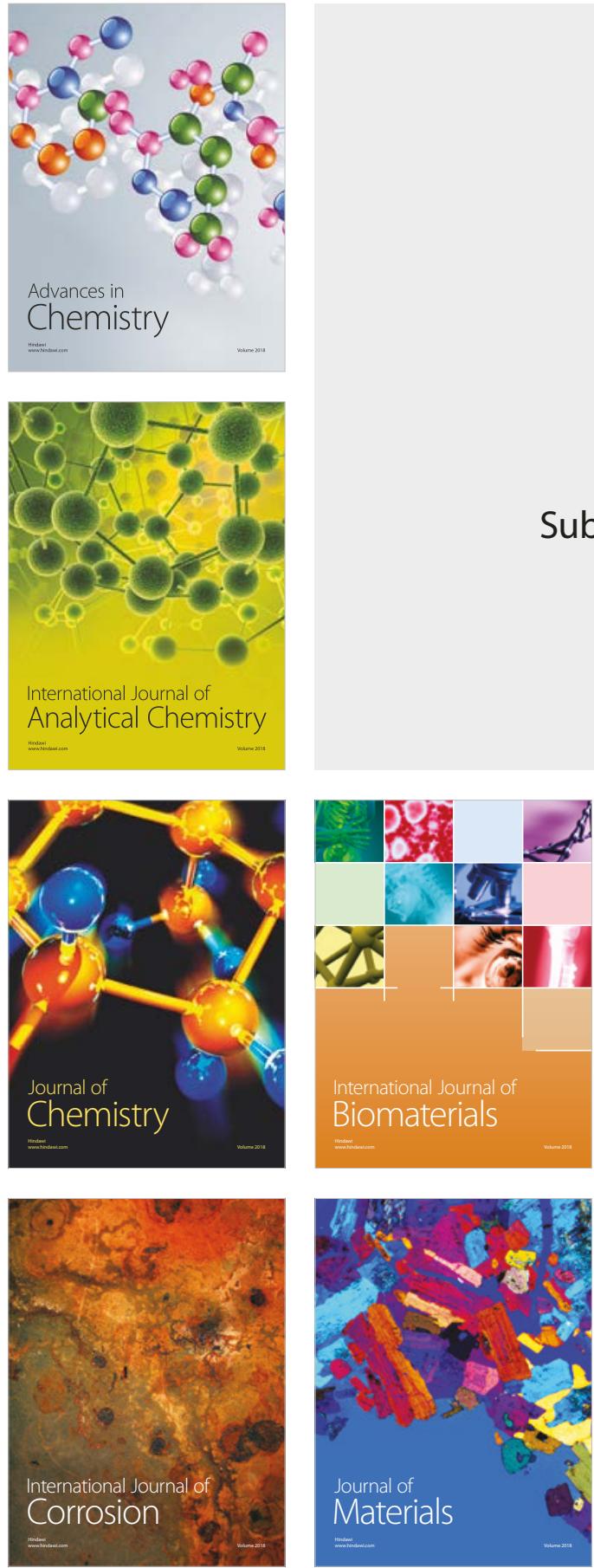

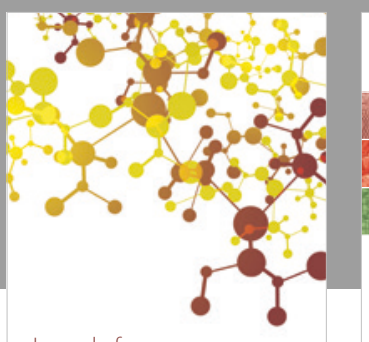

Journal of

Applied Chemistry
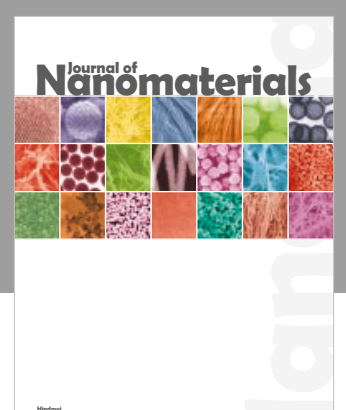

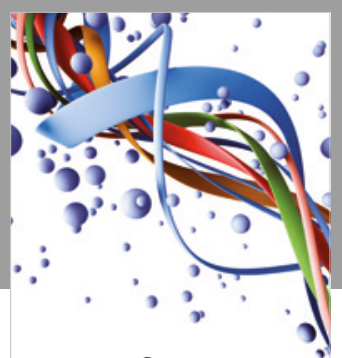

Scientifica

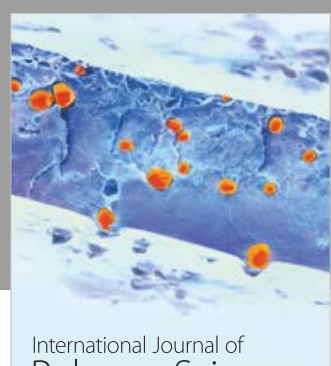

Polymer Science

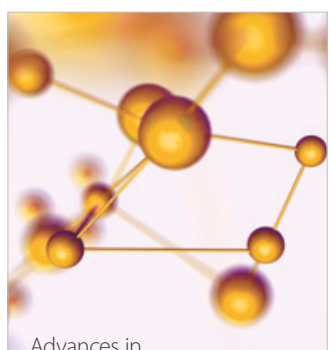

Physical Chemistry
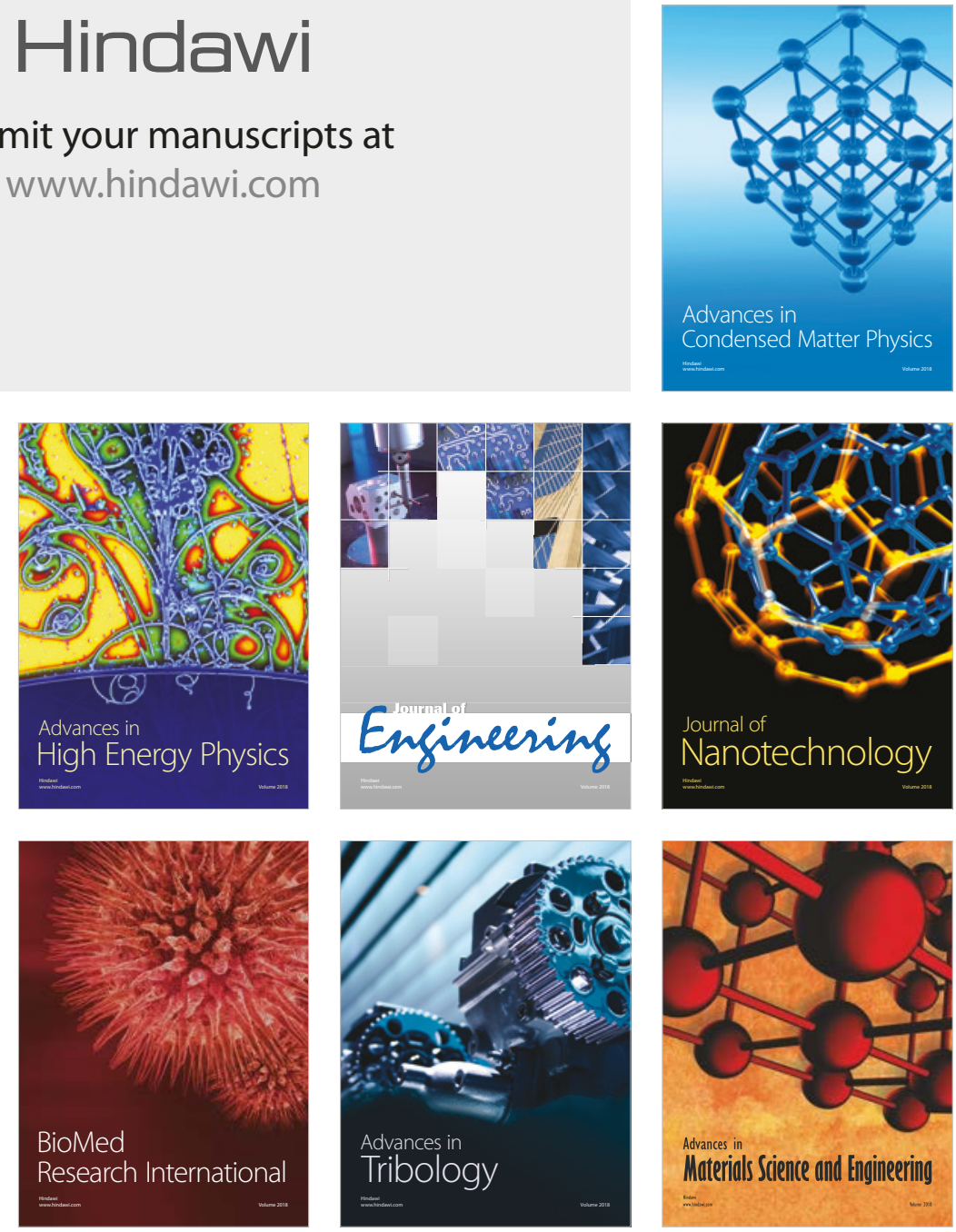